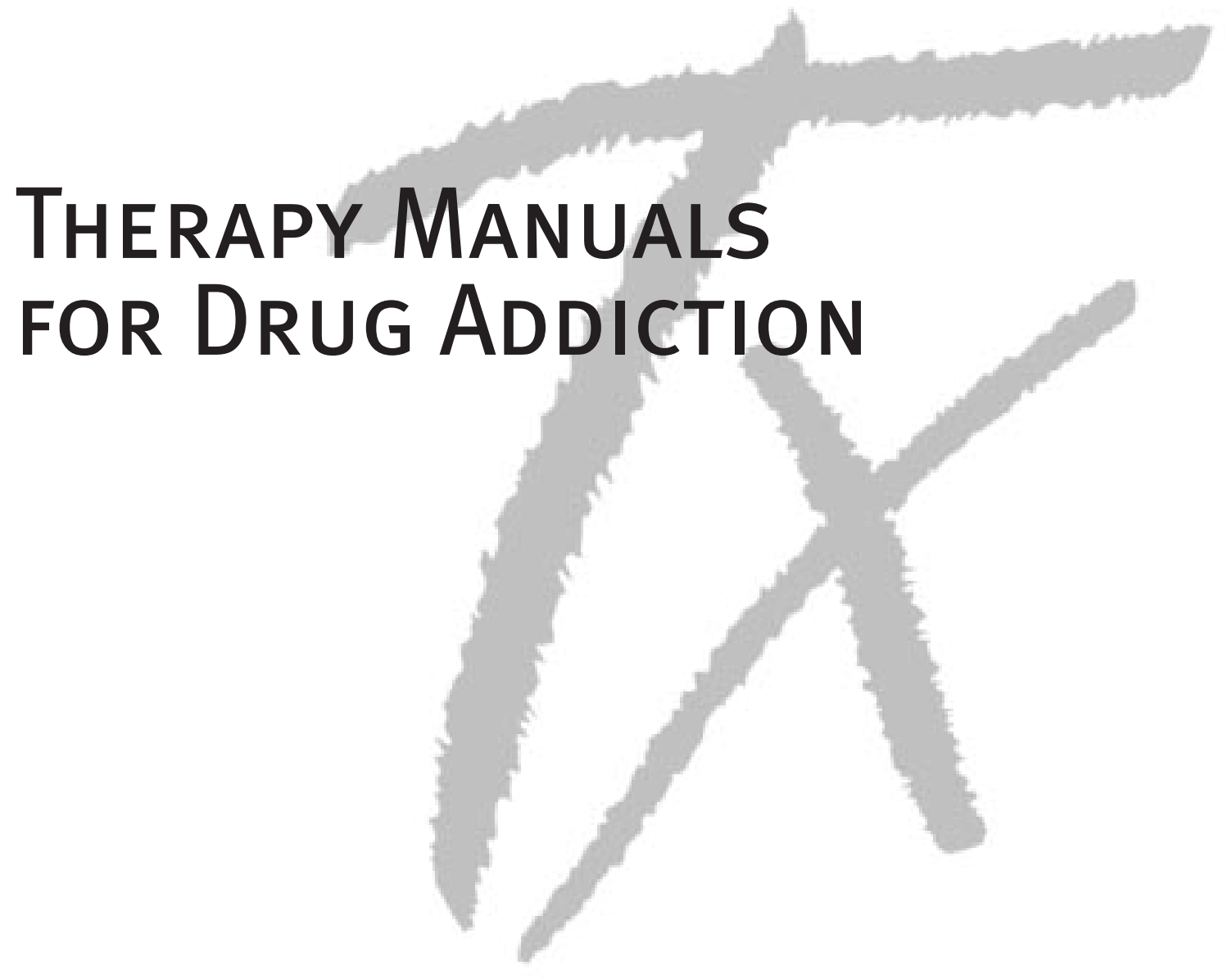

\title{
Brief Strategic Family Therapy for Adolescent Drug Abuse
}

José Szapocznik, Ph.D.

Olga Hervis, M.S.W., L.C.S.W.

Seth Schwartz, Ph.D.

Center for Family Studies

Department of Psychiatry and Behavioral Sciences University of Miami School of Medicine

U.S. Department of Health and Human Services

National Institutes of Health

National Institute on Drug Abuse

6001 Executive Boulevard

Bethesda, Maryland 20892 


\section{ACKNOWLEDGMENTS}

This treatment manual was written by Jose Szapocznik, Ph.D., Olga Hervis, M.S.W., and Seth Schwartz, Ph.D., of the Center for Family Studies, Department of Psychiatry and Behavioral Sciences, at the University of Miami, under contract to the National Institute on Drug Abuse (NIDA). The treatment described in this manual was developed over the course of several decades by a team of researchers and clinicians. Among those who were integral to the development of this manual are: Mercedes Scopetta, who founded the University of Miami Center for Family Studies; Daniel Santisteban, who continues to pioneer culturally sensitive family therapy interventions for Hispanic families; Michael Robbins, who directs the Center's research on in-session processes and their relationship to treatment outcomes; Angel Perez-Vidal, who was the lead therapist in many BSFT studies; and Victoria Mitrani, who has worked intensively on a BSFT-relevant measure of family functioning.

NIDA wishes to thank all who contributed to the development of this manual, including the families who participated in this research, without whom this research would not have been possible.

\section{DISCLAIMER}

The opinions expressed herein are the views of the authors and do not necessarily reflect the official policy or position of the National Institute on Drug Abuse or any other part of the U.S. Department of Health and Human Services. The U.S. Government does not endorse or favor any specific commercial product.

\section{PUBLIC DOMAIN NOTICE}

All material appearing in this report is in the public domain and may be reproduced without permission from the National Institute on Drug Abuse or the authors. Citation of the source is appreciated.

NIH Pub. No. 03-4751

Printed August 2003 


\section{Foreword}

More than 20 years of research has shown that addiction is clearly treatable. Addiction treatment has been effective in reducing drug use and HIV infection, diminishing the health and social costs that result from addiction, and decreasing criminal behavior. The National Institute on Drug Abuse (NIDA), which supports more than 85 percent of the world's research on drug abuse and addiction, has found that behavioral approaches can be very effective in treating cocaine addiction.

To ensure that treatment providers apply the most current scientifically supported approaches to their patients, NIDA has supported the development of the "Therapy Manuals for Drug Addiction" series. This series reflects NIDA's commitment to rapidly applying basic findings in real life settings. The manuals are derived from those used efficaciously in NIDA-supported drug abuse treatment studies. They are intended for use by drug abuse treatment practitioners, mental health professionals, and all others concerned with the treatment of drug addiction.

The manuals present clear, helpful information to aid drug treatment practitioners in providing the best possible care that science has to offer. They describe scientifically supported therapies for addiction and provide guidance on session content and how to implement specific techniques. Of course, there is no substitute for training and supervision, and these manuals may not be applicable to all types of patients nor compatible with all clinical programs or treatment approaches. These manuals should be viewed as a supplement to, but not a replacement for, careful assessment of each patient, appropriate case formulation, ongoing monitoring of clinical status, and clinical judgment.

The therapies presented in this series exemplify the best of what we currently know about treating drug addiction. As our knowledge evolves, new and improved therapies are certain to emerge. We look forward to continuously bringing you the latest scientific findings through manuals and other science-based publications. We welcome your feedback about the usefulness of this manual series and any ideas you have about how it might be improved.

Nora D. Volkow, M.D.

Director

National Institute on Drug Abuse 



\section{Contents}

Page

Foreword $\ldots \ldots \ldots \ldots \ldots \ldots \ldots \ldots \ldots \ldots \ldots \ldots$ iii

Chapter 1 Brief Strategic Family Therapy: An Overview . . . . . 1

Why Brief Strategic Family Therapy? . . . . . . . . . . . . . . . 2

What Are the Goals of Brief Strategic Family Therapy? . . . . . . . . . 3

What Are the Most Common Problems Facing the Family of a

Drug-Abusing Adolescent? . . . . . . . . . . . . . . . . 3

What Is Not the Focus of Brief Strategic Family Therapy? . . . . . . . . . 5

This Manual ........................ 5

Chapter 2 Basic Concepts of Brief Strategic Family Therapy . . . 7

Context . . . . . . . . . . . . . . . . . . . . . . 7

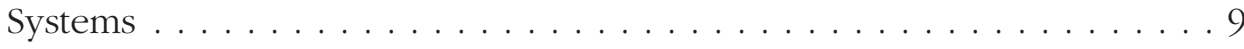

Structure: Patterns of Family Interaction . . . . . . . . . . . . . . 10

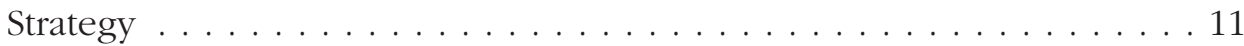

Content Versus Process: A Critical Distinction . . . . . . . . . . . . . 13

Chapter 3 Diagnosing Family System Problems . . . . . . . . . 15

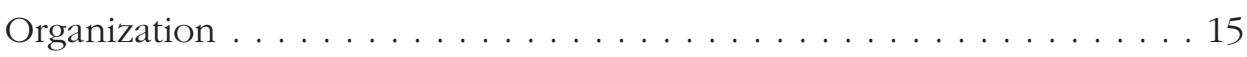

Resonance . . . . . . . . . . . . . . . . . . . . 17

Developmental Stages . . . . . . . . . . . . . . . . . . . . . . . . 19

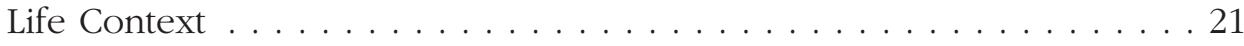

Identified Patient ......................... 22

Conflict Resolution . . . . . . . . . . . . . . . . . . . . . . 22

Chapter 4 Orchestrating Change ................. 25

Establishing a Therapeutic Relationship . . . . . . . . . . . . 25

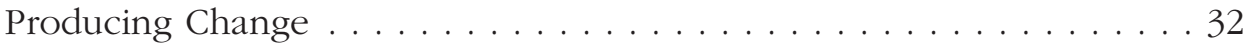


Chapter 5 Engaging the Family Into Treatment . . . . . . . . 43

The Problem ....................... 43

The Task of Coming to Treatment . . . . . . . . . . . . 46

Diagnosing the Interactions That Keep the Family From Coming

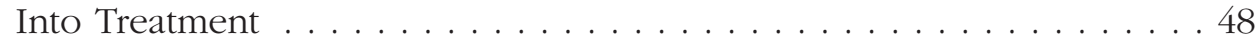

Complementarity: Understanding How the Family "Pieces"

Fit Together to Create Resistance . . . . . . . . . . . . . . . . . . . . 49

Restructuring the Resistance . . . . . . . . . . . . . . . . . . . . . . . . 49

Chapter 6 Clinical Research Supporting Brief Strategic

Family Therapy ........................ 55

Outpatient Brief Strategic Family Therapy Versus Outpatient

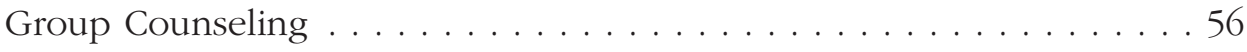

One Person Brief Strategic Family Therapy . . . . . . . . . . . 58

Brief Strategic Family Therapy Engagement . . . . . . . . . . . . . . . . 59

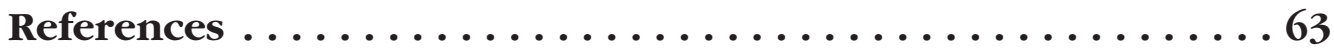

Appendices .......................69

APPENDIX A: Training Counselors in Brief Strategic Family Therapy . . 71

Selecting Counselors . . . . . . . . . . . . . . 71

Required Brief Strategic Family Therapy Training:

Four Phases . . . . . . . . . . . . . . . . . . 72

Required Supervision . . . . . . . . . . . . . . . 75

APPENDIX B: Case Examples . . . . . . . . . . . . . . . . . . 77

Case Example I: The Guerrero Family . . . . . . . . . . . 77

Case Example II: The Hernandez Family . . . . . . . . . 82 


\section{Chapter 1 Brief Strategic Family Therapy: An Overview}

Brief Strategic Family Therapy (BSFT) is a brief intervention used to treat adolescent drug use that occurs with other problem behaviors. These co-occurring problem behaviors include conduct problems at home and at school, oppositional behavior, delinquency, associating with antisocial peers, aggressive and violent behavior, and risky sexual behavior (Jessor and Jessor 1977; Newcomb and Bentler 1989; Perrino et al. 2000).

BSFT is based on three basic principles. The first is that BSFT is a family systems approach. Family systems means that family members are interdependent: What affects one family member affects other family members. According to family systems theory, the drug-using adolescent is a family member who displays symptoms, including drug use and related co-occurring problem behaviors. These symptoms are indicative, at least in part, of what else is going on in the family system (Szapocznik and Kurtines 1989). Just as important, research shows that families are the strongest and most enduring force in the development of children and adolescents (Szapocznik and Coatsworth 1999). For this reason, family-based interventions have been studied as treatments for drug-abusing adolescents and have been found to be efficacious in treating both the drug abuse and related co-occurring problem behaviors (for reviews, see Liddle and Dakof 1995; Robbins et al. 1998; Ozechowski and Liddle 2000).

The second BSFT principle is that the patterns of interaction in the family influence the behavior of each family member. Patterns of interaction are defined as the sequential behaviors among family members that become habitual and repeat over time (Minuchin et al. 1967). An example of this is an adolescent who attracts attention to herself when her two caregivers (e.g., her mother and grandmother) are fighting as a way to disrupt the fight. In extreme cases, the adolescent may suffer a drug overdose or get arrested to attract attention to herself when her mother and grandmother are having a very serious fight.

The role of the BSFT counselor is to identify the patterns of family interaction that are associated with the adolescent's behavior problems. For example, a mother and grandmother who are arguing 
about establishing rules and consequences for a problem adolescent never reach an agreement because the adolescent disrupts their arguments with self-destructive attempts to get attention.

Therefore, the third principle of BSFT is to plan interventions that carefully target and provide practical ways to change those patterns of interaction (e.g., the way in which mother and grandmother attempt but fail to establish rules and consequences) that are directly linked to the adolescent's drug use and other problem behaviors.

\section{Why Brief Strategic Family Therapy?}

The scientific literature describes various treatment approaches for adolescents with drug addictions, including behavioral therapy, multisystemic therapy, and several family therapy approaches. Each of these approaches has strengths.

BSFT's strengths include the following:

- BSFT is an intervention that targets self-sustaining changes in the family environment of the adolescent. That means that the treatment environment is built into the adolescent's daily family life.

- BSFT can be implemented in approximately 8 to 24 sessions. The number of sessions needed depends on the severity of the problem.

- BSFT has been extensively evaluated for more than 25 years and has been found to be efficacious in treating adolescent drug abuse, conduct problems, associations with antisocial peers, and impaired family functioning.

- BSFT is "manualized," and training programs are available to certify BSFT counselors.

- BSFT is a flexible approach that can be adapted to a broad range of family situations in a variety of service settings (e.g., mental health clinics, drug abuse treatment programs, and other social service settings) and in a variety of treatment modalities (e.g., as a primary outpatient intervention, in combination with residential or day treatment, and as an aftercare/continuing-care service to residential treatment).

- BSFT appeals to cultural groups that emphasize family and interpersonal relationships. 


\section{What Are the Goals of Brief Strategic Family Therapy?}

In BSFT, whenever possible, preserving the family is desirable. While family preservation is important, two goals must be set: to eliminate or reduce the adolescent's use of drugs and associated problem behaviors, known as "symptom focus," and to change the family interactions that are associated with the adolescent's drug abuse, known as "system focus." An example of the latter occurs when families direct their negative feelings toward the drug-abusing youth. The parents' negativity toward the adolescent directly affects his or her drug abuse, and the adolescent's drug abuse increases the parents' negativity. At the family systems level, the counselor intervenes to change the way family members act toward each other (i.e., patterns of interaction). This will prompt family members to speak and act in ways that promote more positive family interaction, which, in turn, will make it possible for the adolescent to reduce his or her drug abuse and other problematic behaviors.

\section{What Are the Most Common Problems Facing the Family of a Drug-Abusing Adolescent?}

The makeup and dynamics of the family are discussed in terms of the adolescent's symptoms and the family's problems.

\author{
The Family Profile \\ of a Drug-Abusing \\ Adolescent
}

Research shows that many adolescent behavior problems have common causes and that families, in particular, play a large role in those problems in many cases (Szapocznik and Coatsworth 1999). Some of the family problems that have been identified as linked to adolescent problem behaviors include:

- Parental drug use or other antisocial behavior

- Parental under- or over-involvement with the adolescent

- Parental over- or under-control of the adolescent

- Poor quality of parent-adolescent communication

- Lack of clear rules and consequences for adolescent behavior

- Inconsistent application of rules and consequences for adolescent behavior

- Inadequate monitoring and management of the adolescent's activities with peers

- Lack of adult supervision of the adolescent's activities with peers

- Poor adolescent bonding to family

- Poor family cohesiveness 


\section{The Behavioral Profile of a Drug-Abusing Adolescent}

Some adolescents may have families who had these problems before they began using drugs (Szapocznik and Coatsworth 1999). Other families may have developed problems in response to the adolescent's problem behaviors (Santisteban et al. in press).

Because family problems are an integral part of the profile of drugabusing adolescents and have been linked to the initiation and maintenance of adolescent drug use, it is necessary to improve conditions in the youth's most lasting and influential environment: the family. BSFT targets all of the family problems listed on page 3.

Adolescents who need drug abuse treatment usually exhibit a variety of externalizing behavior problems. These may include:

- School truancy

- Delinquency

- Associating with antisocial peers

- Conduct problems at home and/or school

- Violent or aggressive behavior

- Oppositional behavior

- Risky sexual behavior

Families of drug-abusing adolescents exhibit high degrees of negativity (Robbins et al. 1998). Very often, this negativity takes the form of family members blaming each other for both the adolescent's and the family's problems. Examples might include a parent who refers to her drug-abusing son as "no good" or "a lost cause." Parents or parent figures may blame each other for what they perceive as a failure in raising the child. For example, one parent may accuse the other of having been a "bad example," or for not "being there" when the youngster needed him or her. The adolescent, in turn, may speak about the parent accused of setting a bad example with disrespect and resentment. The communication among family members is contaminated with anger, bitterness, and animosity. To the BSFT counselor, these signs of emotional or affective distress indicate that the work of changing dysfunctional behaviors must start with changing the negative tone of the family members' emotions and the negative content of their interactions. Research shows that when family negativity is reduced early in treatment, families are more likely to remain in therapy (Robbins et al. 1998). 


\section{What Is Not the Focus of Brief Strategic Family Therapy?}

BSFT has not been tested with adult addicts. For this reason, BSFT is not considered a treatment for adult addiction. Instead, when a parent is found to be using drugs, a counselor needs to decide the severity of the parent's drug problem. A parent who is moderately involved with drugs can be helped as part of his or her adolescent's BSFT treatment. However, if a parent is drug dependent, the BSFT counselor should work to engage the parent in drug abuse treatment. If the parent is unwilling to get drug abuse treatment, the BSFT counselor should work to protect and disengage the adolescent from the drug dependent parent. This is done by creating an interpersonal wall or boundary that separates the adolescent and non-drug-using family members from the drug dependent parent(s). This process is discussed in Chapter 4 in the section on "Working With Boundaries and Alliances," beginning on page 36.

\section{This Manual}

This manual introduces counselors to concepts that are needed to understand the family as a vital context within which adolescent drug abuse occurs. It also describes strategies for creating a therapeutic relationship with families, assessing and diagnosing maladaptive patterns of family interaction, and changing patterns of family interaction from maladaptive to adaptive. This manual assumes that therapists who adopt these BSFT techniques will be able to engage and retain families in drug abuse treatment and ultimately cause them to behave more effectively. Chapter 2 will discuss the basic theoretical concepts of BSFT. Chapter 3 will present the BSFT diagnostic approach, and Chapter 4 will explain how change is achieved. Chapter 5 is a detailed discussion of how to engage resistant families of drug-abusing adolescents in treatment. Chapter 6 summarizes some of the research that supports the use of BSFT with adolescents. The manual also has two appendices, one on training counselors to implement BSFT and another presenting case examples from the authors' work. Concepts and techniques discussed by Minuchin and Fishman (1981) have been adapted in this BSFT manual for application to drug-abusing adolescents. Additional discussion of BSFT can be found in Szapocznik and Kurtines (1989). 



\section{Chapter 2 Basic Concepts of Brief Strategic Family Therapy}

The previous chapter introduced the underlying philosophy of BSFT: to help families help themselves and to preserve the family unit, whenever possible. The remainder of this manual focuses more directly on BSFT as a strategy to treat adolescent drug abuse and its associated behavior problems. This chapter presents the most basic concepts of the BSFT approach. It begins with a discussion of five theoretical concepts that comprise the basic foundation of BSFT. Some of these concepts may be new for drug abuse counselors. The five concepts discussed in this chapter are:

- Context

- Systems

- Structure

- Strategy

- Content versus process

\section{Context}

Family as Context
The social influences an individual encounters have an important impact on his or her behavior. Such influences are particularly powerful during the critical years of childhood and adolescence. The BSFT approach asserts that the counselor will not be able to understand the adolescent's drug-abusing behavior without understanding what is going on in the various contexts in which he or she lives. Drug-abusing behavior does not happen in a vacuum; it exists within an environment that includes family, peers, neighborhood, and the cultures that define the rules, values, and behaviors of the adolescent.

Context, as defined by Urie Bronfenbrenner (1977, 1979, 1986, 1988), includes a number of social contexts. The most immediate are those that include the youth, such as family, peers, and neighborhoods. Bronfenbrenner recognized the enormous influence the family has, and he suggested that the family is the primary context in which the 


\section{Peers as Context}

Neighborhood as Context

\section{Culture as Context}

child learns and develops. More recent research has supported socializing children and adolescents (for reviews, see Perrino et al. 2000; Szapocznik and Coatsworth 1999).

Considerable research has demonstrated the influences that friends' attitudes, norms, and behaviors have on adolescent drug abuse (Brook et al. 1999; Newcomb and Bentler 1989; Scheier and Newcomb 1991). Moreover, drug-using adolescents often introduce their peers to and supply them with drugs (Bush et al. 1994). In the face of such powerful peer influences, it may seem that parents can do little to help their adolescents.

However, recent research suggests that, even in the presence of drugusing (Steinberg et al. 1994) or delinquent (Mason et al. 1994) peers, parents can wield considerable influence over their adolescents. Most of the critical family issues (e.g., involvement, control, communication, rules and consequences, monitoring and supervision, bonding, family cohesion, and family negativity) have an impact on how much influence parents can have in countering the negative impact peers have on their adolescents' drug use.

The interactions between the family and the context in which the family lives may also be important to consider. A family functions within a neighborhood context, family members live in a particular neighborhood, and the children in the family are students at a particular school. For instance, to effectively manage a troubled 15year-old's behavioral problems in a particular neighborhood, families may have to work against high drug availability, crime, and social isolation. In contrast, a small town in a semi-rural community may have a community network that includes parents, teachers, grandparents, and civic leaders, all of whom collaborate in raising the town's children. Neighborhood context, then, can introduce additional challenges to parenting or resources that should be considered when working with families.

Bronfenbrenner also suggested that families, peers, and neighborhoods exist within a wider cultural context that influences the family and its individual members. Extensive research on culture and the family has demonstrated that the family and the child are influenced by their cultural contexts (Santisteban et al. 2003; Szapocznik and Kurtines 1993). Much of the researchers' work has examined the ways in which minority families' values and behaviors have an impact on the relationship between parents and children and affect adolescents' involvement with drug abuse and its associated problems (Santisteban et al. 2003; Szapocznik and Kurtines 1980, 1993; Szapocznik et al. 1978). 


\section{Counseling as Context}

\section{Systems}

\section{Family Systemic Influences}

The counseling situation itself is a context that is associated with a set of rules, expectations, and experiences. The cultures of the client (i.e., the family), the counselor, the agency, and the funding source can all affect the nature of counseling as can the client's feelings about how responsive the "system" is to his or her needs.

Systems are a special case of context. A system is made up of parts that are interdependent and interrelated. Families are systems that are made up of individuals (parts) who are responsive (interrelated) to each other's behaviors.

"Systems" implies that the family must be viewed as a whole organism. In other words, it is much more than merely the sum of the individuals or groups that it comprises. During the many years that a family is together, family members develop habitual patterns of behavior after having repeated them thousands of times. In this way, each individual member has become accustomed to act, react, and respond in a specific manner within the family. Each member's actions elicit a certain reaction from another family member over and over again over time. These repetitive sequences give the family its own form and style.

The patterns that develop in a family actually shape the behaviors and styles of each of its members. Each family member has become accustomed to behaving in certain ways in the family. Basically, as one family member develops certain behaviors, such as a responsible, take-control style, this shapes other family members' behaviors. For example, family members may allow the responsible member to handle logistics. At the same time, the rest of the family members may become less responsible. In this fashion, family members complement rather than compete with one another. These behaviors have occurred so many times, often without being thought about, that they have shaped the members to fit together like pieces of a puzzle-a perfect, predictable fit.

Family influences may be experienced as an "invisible force." Family members' behavior can vary considerably. They may act much differently when they are with other family members than when they are with people outside the family. By its very presence, the family system shapes the behaviors of its members. The invisible forces (i.e., systemic influences) that govern the behaviors of family members are at work every time the family is together. These "forces" include such things as spoken or unspoken expectations, alliances, rules for managing conflicts, and implicitly or explicitly assigned roles. 


\section{The Principle of Complementarity}

In the case of an adolescent with behavior problems, the family's lack of skills to manage a misbehaving youth can create a force (or pattern of interaction) that makes the adolescent inappropriately powerful in the family. For example, when the adolescent dismisses repeated attempts by the parents to discipline him or her, family members learn that the adolescent generally wins arguments, and they change their behavior accordingly. Once a situation like this arises in which family expectations, alliances, rules, and so on have been reinforced repeatedly, family members may be unable to change these patterns without outside help.

The idea that family members are interdependent, influencing and being influenced by each other, is not unique to BSFT. Using different terminology, the theoretical approach underlying behaviorally oriented family treatments might explain these mutual influences as family members both serving as stimuli for and eliciting responses from one another (Hayes et al. 1999). The theoretical approach underlying existential family treatments might describe this influence as family members either supporting or constraining the growth of other family members (Lantz and Gregoire 2000). What distinguishes BSFT from behaviorally oriented and existential family treatments is its focus on the family system rather than on individual functioning.

BSFT assumes that a drug-abusing adolescent will improve his or her behavior when the family learns how to behave adaptively. This will happen because family members, who are "linked" emotionally, are behaviorally responsive to each other's actions and reactions. In BSFT, the Principle of Complementarity holds that for every action by a family member there is a corresponding reaction from the rest of the family. For instance, often children may have learned to coerce parents into reinforcing their negative behavior-for example, by throwing a temper tantrum and stopping only when the parents give in (Patterson 1982; Patterson and Dishion 1985; Patterson et al. 1992). Only when the parents change their behavior and stop reinforcing or "complementing" negative behavior will the child change.

\section{Structure: Patterns of Family Interaction}

An exchange among family members, either through actions or conversations, is called an interaction. In time, interactions become habitual and repetitive, and thus are referred to as patterns of interaction (Minuchin 1974). Patterns of family interaction are the habitual and repeated behaviors family members engage in with each other. More specifically, the patterns of family interaction are comprised of linked chains of behavior that occur among family members. A simple example can be illustrated by observing that family members choose to sit at the same place at the dinner table every day. Where people sit may make it easier for them to speak with each other and 
not with others. Consequently, a repetitive pattern of interaction reflected in a "sitting" pattern is likely to predict the "talking" pattern. A large number of these patterns of interaction will develop in any system. In families, this constellation of repetitive patterns of interaction is called the family "structure."

The repetitive patterns of interaction that make up a family's structure function like a script for a play that the actors have read, memorized, and re-enact constantly. When one actor says a certain line from the script or performs a certain action, that is the cue for other actors to recite their particular lines or perform their particular actions. The family's structure is the script for the family play.

Families of drug-abusing adolescents tend to have problems precisely because they continue to interact in ways that allow the youths to misbehave. BSFT counselors see the interactions between family members as maintaining or failing to correct problems, and so they make these interactions the targets of change in therapy. The adaptiveness of an interaction is defined in terms of the degree to which it permits the family to respond effectively to changing circumstances.

\section{Strategy}

\section{The Three Ps of Effective Strategy}

As its second word suggests, a fundamental concept of Brief Strategic Family Therapy is strategy. BSFT interventions are strategic (Haley 1976) in that they are practical, problem-focused, and planned.

\section{Practical}

BSFT uses strategies that work quickly and effectively, even though they might seem unconventional. BSFT may use any technique, approach, or strategy that will help change the maladaptive interactions that contribute to or maintain the family's presenting problem. Some interventions used in BSFT may seem "outside the theory" because they may be borrowed from other treatment modalities, such as behavior modification. For example, behavioral contracting, in which patients sign a contract agreeing to do or not to do certain things, is used frequently as part of BSFT because it is one way to re-establish the parent figures as the family leaders. Frequently, the counselor's greatest challenge is to get the parent(s) to behave in a measured and predictable fashion. Behavioral contracting may be an ideal tool to use to accomplish this. The BSFT counselor uses whatever strategies are most likely to achieve the desired structural (i.e., interactional) changes with maximum speed, effectiveness, and permanence. Often, rather than trying to capture every problematic aspect of a family, the BSFT counselor might emphasize one aspect because it serves to move the counseling in a particular direction. For example, a counselor might emphasize a mother's permissiveness because it is related to her daughter's drug abuse and not emphasize the mother's relationship with her own parents, which may also be problematic. 


\section{Problem-Focused}

The BSFT counselor works to change maladaptive interactions or to augment existing adaptive interactions (i.e., when family members interact effectively with one another) that are directly related to the presenting problem (e.g., adolescent drug use). This is a way of limiting the scope of treatment to those family dynamics that directly influence the adolescent's symptoms. The counselor may realize that the family has other problems. However, if they do not directly affect the adolescent's problem behaviors, these other family problems may not become a part of the BSFT treatment. It is not that BSFT cannot focus on these other problems. Rather, the counselor makes a choice about what problems to focus on as part of a time-limited counseling program. For example, the absence of clear family rules about appropriate and inappropriate behavior may directly affect the adolescent's drug-using behavior, but marital problems might not need to be modified to help the parents increase their involvement, control, monitoring and supervision, rule setting, and enforcement of rules in the adolescent's life.

Most families of drug-abusing adolescents are likely to experience multiple problems in addition to the adolescent's symptoms. Frequently, counselors complain that "this family has so many problems that I don't know where to start." In these cases, it is important for the counselor to carefully observe the distinction between "content" and "process" (see "Content Versus Process: A Critical Distinction," p. 13). Normally, families with many different problems (a multitude of contents) are unable to tackle one problem at a time and keep working on it until it has been resolved (process). These families move (process) from one problem to another (content) without being able to focus on a single problem long enough to resolve it. This is precisely how they become overwhelmed with a large number of unresolved problems. It is their process, or how they resolve problems, that is faulty. The counselor's job is to help the family keep working on (process) a single problem (content) long enough to resolve it. In turn, the experience of resolving the problem may help change the family's process so that family members can apply their newly acquired resolution skills to other problems they are facing. If the counselor gets lost in the family's process of shifting from one content/ problem to another, he or she may feel overwhelmed and, thus, be less likely to help the family resolve its conflicts.

\section{Planned}

In BSFT, the counselor plans the overall counseling strategy and the strategy for each session. "Planned" means that after the counselor determines what problematic interactions in the family are contributing to the problem, he or she then makes a clear and well-organized plan to correct them. 


\section{Content Versus Process: A Critical Distinction}

In BSFT, the "content" of therapy refers to what family members talk about, including their explanations for family problems, beliefs about how problems should be managed, perspectives about who or what causes the problems, and other topics. In contrast, the "process" of therapy refers to how family members interact, including the degree to which family members listen to, support, interrupt, undermine, and express emotion to one another, as well as other ways of interacting. The distinction between content and process is absolutely critical to BSFT. To be able to identify repetitive patterns of interaction, it is essential that the BSFT counselor focus on the process rather than the content of therapy.

Process is identified by the behaviors that are involved in a family interaction. Nonverbal behavior is usually indicative of process as is the manner in which family members speak to one another.

Process and content can send contradictory messages. For example, while an adolescent may say, "Sure Mom, I'll come home early," her sarcastic gesture and intonation may indicate that she has no intention of following her mother's request that she be home early. Generally, the process is more reliable than the content because behaviors or interactions (e.g., disobeying family rules) tend to repeat over time, while the specific topic involved may change from interaction to interaction (e.g., coming home late, not doing chores, etc.).

The focus of BSFT is to change the nature of those interactions that constitute the family's process. The counselor who listens to the content and loses sight of the process won't be able to make the kinds of changes in the family that are essential to BSFT work. Frequently, a family member will want to tell the counselor a story about something that happened with another family member. Whenever the counselor hears a story about another family member, the counselor is allowing the family to trap him or her in content. If the counselor wants to refocus the session from content to process, when Mom says, "Let me tell you what my son did...," the counselor would say: "Please tell your son directly so that I can hear how you talk about this." When Mom talks to her son directly, the therapist can observe the process rather than just hear the content when Mom tells the therapist what her son did. Observations like these will help the therapist characterize the problematic interactions in the family. 



\title{
Chapter 3 Diagnosing Family System Problems
}

The BSFT approach to assessing and diagnosing family system problems differs drastically from that used by other kinds of psychotherapies. Unlike other psychotherapies that assess and diagnose by focusing on content, such as talking about a family's history, BSFT assesses and diagnoses by identifying the current family process. BSFT focuses on the nature and characteristics of the interactions that occur in the family and either help or hinder the family's attempts to get rid of the adolescent's problem behaviors.

The following six elements of the family's interactions are examined in detail:

- Organization

- Resonance

- Developmental stages

- Life context

- Identified patient

- Conflict resolution

\section{Organization}

\author{
Leadership
}

As repetitive patterns of interaction in a family occur over time, they give the family a specific form, or "organization." Three aspects of this organization are examined below: leadership, subsystem organization, and communication flow.

Leadership is defined as the distribution of authority and responsibility within the family. In functional two-parent families, leadership is in the hands of the parents. In modern societies, both parents usually share authority and decisionmaking. Frequently, in one-parent families, the parent shares some of the leadership with an older child. The latter situation has the potential for creating problems. In the case of a single parent living within an extended family framework, leadership may be 
shared with an uncle, aunt, or grandparent. In assessing whether leadership is adaptive, BSFT counselors look at hierarchy, behavior control, and guidance.

Counselors look at the hierarchy, or the way a family is ranked, to see who is in charge of leading the family and who holds the family's positions of authority. BSFT assumes that the leadership should be with the parent figures, with supporting roles assigned to older family members. Some leadership responsibilities can be delegated to older children, as long as those responsibilities are not overly burdensome, are age-appropriate, and are delegated by parent figures rather than usurped by the children. BSFT counselors look at behavior control in the family to see who, if anyone, keeps order and doles out discipline in the family. Effective behavior control typically means that the parents are in charge and the children are acting in accordance with parental rules. Guidance refers to the teaching and mentoring functions in the family. BSFT assesses whether these roles are filled by appropriate family members and whether the youngsters' needs for guidance are being met.

Subsystem Organization
Families have both formal subsystems (e.g., spouses, siblings, grandparents, etc.) and informal subsystems (e.g., the older women, the people who manage the money, the people who do the housekeeping, the people who play chess). Important subsystems must have a certain degree of privacy and independence. BSFT looks at issues such as the adequacy or appropriateness of the subsystems in a family. It also assesses the nature of the relationships that give rise to these subsystems and especially looks at subsystem membership, triangulation, and communication flow, which are discussed below.

\section{Subsystem Membership}

BSFT identifies the family's subsystems, which are small groups within the family that are composed of family members with shared characteristics, such as age, gender, role, interests, or abilities. BSFT counselors pay particular attention to the appropriateness of each subsystem's membership and to the boundaries between subsystems. For example, parent figures should form a subsystem, while siblings of similar ages should also form a subsystem, and each of these subsystems should be separate from the others.

Subsystems that cross generations (e.g., between a parent and one child) cause trouble because such relationships blur hierarchical lines and undermine a parent's ability to control behavior. Relationships in which one parent figure and a child unite against another parent figure are called "coalitions." Coalitions are destructive to family functioning and are very frequently seen in families of drug-abusing adolescents. In these cases, the adolescent has gained so much power through this relationship that he or she dares to constantly challenge authority and gets away with it. The adolescent has this power to be rebellious, disobedient, and out of control by having gained the support of one 
parent who, to disqualify the other parent, enables the adolescent's inappropriate behavior.

\section{Triangulation}

Sometimes when two parental authority figures have a disagreement, rather than resolving the disagreement between themselves, they involve a third, less powerful person to diffuse the conflict. This process is called "triangulation." Invariably this triangulated third party, usually a child or an adolescent, experiences stress and develops symptoms of this stress, such as behavior problems. Triangles always spell trouble because they prevent the resolution of a conflict between two authority figures. The triangulated child typically receives the brunt of much of his or her parents' unhappiness and begins to develop behavior problems that should be understood as a call for help.

\section{Communication Flow}

The final category of organization looks at the nature of communication. In functional families, communication flow is characterized by directness and specificity. Good communication flow is the ability of two family members to directly and specifically tell each other what they want to say. For example, a declaration such as, "I don't like it when you yell at me," is a sign of good communication because it is specific and direct. Indirect communications are problematic. Take, for example, a father who says to his son, "You tell your mother that she better get here right away," or the mother who tells the father, "You better do something about Johnny because he won't listen to me." In these two examples, the communication is conducted through a third person. Nonspecific communications are also troublesome, as in the case of the father who tells his son, "You are always in trouble." The communication would be more constructive if the father would explain very clearly what the problem is. For example: "I get angry when you come home late."

\section{Resonance}

"Resonance" defines the emotional and psychological accessibility or distance between family members. A 6-year-old son who hangs onto his mother's skirt at his birthday party may be said to be overly close to her. A mother who cries when her daughter hurts is emotionally very close. A father who does not care that his son is in trouble with the law may be described as psychologically and emotionally distant.

One of the key concepts related to resonance is boundaries. An interpersonal boundary, just as the words imply, is a way of denoting where one person or group of people ends and where the next one begins. People set their own boundaries when they let others know which behaviors entering their personal space they will allow and which ones they will not allow. In families, resonance refers to the psychological and emotional closeness or distance between any two 


\section{Enmeshment and Disengagement}

Resonance and Culture family members. This psychological and emotional distance is established and maintained by the boundaries that exist between family members. In particular, the boundaries between two family members determine how much affect, or emotion, can get through from one person to the other. If the boundaries between two people are very permeable, then a lot gets through, and there is high resonancegreat psychological and emotional closeness-between them. One's happiness becomes the other's happiness. If the boundaries between two people are overly rigid, then each person may not even know what the other is feeling.

The firmness and clarity of boundaries reflect the degree of differentiation within a family system. At one extreme, boundaries can be extremely impermeable. If this is the case, the emotional and psychological distance between family members is too large, and these family members are said to be "disengaged" from each other. At the other extreme, boundaries can be far too permeable or almost nonexistent. When boundaries are that permeable, the emotional and psychological closeness between people is too great, and these family members are said to be "enmeshed." Each of these extremes is problematic and becomes a target for intervention.

Interactions that are either enmeshed or disengaged can cause problems. When these interactions cause problems, they need to be altered to establish a better balance between the closeness and distance that exists between different family members. For each family, there is an ideal balance between closeness and distance that allows cooperation and separation.

Resonance needs to be assessed in the context of culture. This is important because some cultures encourage family members to be very close with each other, while other cultures encourage greater distance. One important aspect of culture involves the racial or ethnic groups with which families identify themselves. For example, Hispanics are more likely than white Americans to be close and, thus, appear more enmeshed (have higher resonance) (e.g., Woehrer 1989). Similarly, an Asian father may be quite distant or disengaged from the women in his family, which is considered natural in his culture (Sue 1998). However, whether the culture dictates the distance between family members, it is important for counselors to question if a particular way of interacting is causing problems for the family. In other words, even if an interaction is typical of a culture, if it is causing symptoms, then it may need to be changed. This type of situation must be handled with great knowledge and sensitivity to demonstrate respect for the culture and to allow family members to risk making a change that is foreign to their culture. 


\section{Enmeshment (high resonance) and Disengagement (low resonance)}

Sometimes "enmeshment" (excessive closeness) and "disengagement" (excessive distance) can occur at the same time within a single family. This happens frequently in families of drug-abusing youths, when one parent is sometimes very protective and is closely allied with the youth (i.e., enabling), while the other parent may be somewhat disinterested and distant.

BSFT counselors look for certain behaviors in a family that are telltale signs of either enmeshment or disengagement. Obviously, some of these behaviors may happen in any family. However, when a large number of these behaviors occur or when some occur in an extreme form, they are likely to reflect problems in the family's patterns of interaction. Easily observable symptoms of enmeshment include one person answering for another, one person finishing another's statements, and people interrupting each other. Observable symptoms of disengagement include one family member who wants to be separated from another or a family member who rarely speaks or is spoken about.

\section{Developmental Stages}

Individuals go through a series of developmental stages, ranging from infancy to old age. Certain conditions, roles, and responsibilities typically occur at each stage. Families also go through a series of developmental stages. For family members to continue to function adaptively at each developmental stage, they need to behave in ways that are appropriate for the family's developmental level.

Each time a developmental transition is reached, the family is confronted by a new set of circumstances. As the family attempts to adapt to the new circumstances, it experiences stress. Failure to adapt, to make the transition, to give up behaviors that were used successfully at a previous developmental stage, and to establish new behaviors that are adaptive to the new stage will cause some family members to develop new behavior problems. Perhaps one of the most stressful developmental changes occurs when children reach adolescence. This is the stage at which a large number of families are not able to adapt to developmental changes (e.g., from direct guidance to leadership and negotiation). Parents must be able to continue to be involved and monitor their adolescent's life, but now they must do it from a distinctly different perspective that allows their daughter or son to gain autonomy.

At each developmental stage, certain roles and tasks are expected of different family members. One way to determine whether the family has successfully overcome the various developmental challenges that it has confronted is to assess the appropriateness of the roles and tasks that have been assigned to each family member, considering the age and position of each person within the family. When a family's developmental stage is analyzed, four major sets of tasks and roles 


\section{Assessing Appropriate Developmental Functioning}

must be assessed: (1) Parenting tasks and roles are concerned with the parent figures' ability to act as parents at a level consistent with the age of the children; (2) Marital tasks and roles assess how well spouses cooperate and share parenting functions; (3) Sibling tasks and roles assess whether the children and adolescents are behaving in an age-appropriate fashion; and (4) Extended family's tasks and roles target the support for and intrusion into parenting functions from, for example, grandparents, aunts, and uncles, if extended family members are part of the household or share in parenting responsibilities.

Developmental transitions may be stressful. They are likely to cause family shake-ups because families may continue to approach new situations in old ways, thus making it possible for conflict to develop. Most often, families come to the attention of counselors precisely at these times. Of all of these developmental milestones, reaching adolescence appears to be one of the most risky and critical stages in which drug abuse can occur in most ethnic groups (Steinberg 1991; Vega and Gil 1999). Although the adolescent is the family member who is most likely to behave in problematic ways, often other members of the family, such as parents, also exhibit signs of troublesome or maladaptive behaviors and feelings (Silverberg 1996).

Careful judgments are needed to determine what is developmentally appropriate and/or inappropriate for each family member. It is particularly difficult to make these judgments when assessing the tasks and roles of children and extended family members. In every instance, the BSFT counselor should take into account the family's cultural heritage when making these judgments. For example, it is useful to know that some traditional African-American and Hispanic families tend to protect their children longer than non-Hispanic whites do (White 1994). Thus, it would not be unusual for children to have a longer period of dependence among traditional Hispanic groups than among non-Hispanic white families. Similarly, it would not be unusual for the African-American caretaker of a 12-year-old to continue to behave in an authoritarian manner without the child rebelling or considering it odd. In fact, researchers have suggested that African-American inner city youths experience an authoritarian command as caring, while a child from another cultural group might experience it as rejecting (Mason et al. 1994). However, as suggested earlier, as an adolescent in the United States grows older, his or her parent, who may be from any culture and in any setting, may have to moderate his or her level of control and increase his or her authoritative parenting, or the youth may rebel.

It is often difficult for parents to determine what is developmentally appropriate for children of different ages; for example, how much or how little responsibility should a child 6,10 , or 16 years old have in a household? In families of drug-abusing and conduct-disordered adolescents, parents and their children often have a difficult time determining what is developmentally appropriate for a child's age. 
One of the main problems family members encounter is how to determine the degree of supervision and autonomy that children should have at each age level. This is a highly complex and conflictive area, even for the best of parents, because as children grow older, they experience considerable pressure from their peers to demonstrate increasing independence. It is also complex because many parents are not aware of what might be the norm in today's society. Therefore, they may allow too little or too much autonomy, based either on their own comfort or discomfort level, their own experience, and/or their culture. Moreover, children's peer groups may vary considerably in the level of autonomy they expect from parents. In working with the notion of "developmental appropriateness," a BSFT counselor needs to examine issues such as roles and functions, rights and responsibilities, limits and consequences, as they are applied to the adolescents in the family. Examples of these standards are available from adolescent development research (Steinberg 1998).

\section{Life Context}

Antisocial Peers

Parent Support Systems and Social Resources

Juvenile Justice System
While the dimensions of family functioning discussed up to now are all within the family, life context refers to what happens in the family's relationship to its social context. The life context of the family includes the extended family, the community, the work situation, adolescent peers, schools, courts, and other groups that may have an impact on the family, either as stressors or as support systems.

A careful analysis of the life context is useful in many situations involving the treatment of substance abuse. For example, a youngster who uses drugs may be involved with a deviant or antisocial peer group. These friendships affect the youth and family in an adverse way and will certainly need to be modified to successfully eliminate the youth's drug use. Parents need help to identify less acceptable and more acceptable adolescent peers so that they can encourage their teens to associate with more desirable peers and discourage them from associating with less desirable peers.

Parenting is a difficult task. Parents often lack adequate support systems for parenting. Parents need support from friends, extended family members, and other parents (Henricson and Roker 2000). The availability of support systems needs to be assessed, particularly in the case of single-parent families. The availability of social resources needs to be assessed, both in terms of what is already being used or what could potentially be used.

Increasingly, probation officers and the courts have become critical players in the families of drug-abusing adolescents. It is the BSFT counselor's job to assess how juvenile justice representatives such as probation officers interact with the family to determine whether they 
are supporting or undermining the family. One way to assess the probation officer's role, for example, is to invite him or her to participate in a family therapy session.

\section{Identified Patient}

\section{Conflict Resolution}

While solving differences of opinion is always challenging, it is much more challenging when it is done in the context of a conflictive relationship that is high in negativity. The following are five different ways in which families can approach or manage conflicts. Some are adaptive and some are not. In the case of drug-abusing adolescents, with few exceptions, the first four tend to be ineffective, whereas the fifth tends to be effective in most situations:

- Denial

- Avoidance

- Diffusion

- Conflict emergence without resolution

- Conflict emergence with resolution 
Denial

Avoidance

Diffusion

Conflict Emergence Without Resolution

\section{Conflict Emergence With Resolution}

"Denial" refers to a situation in which conflict is not allowed to emerge. Sometimes this is done by adopting the attitude that everything is all right. At other times, conflict is denied by arranging situations to avoid confrontation or establishing unwritten rules with which no one dares to disagree outwardly, regardless of how they feel. The classic denial case is the one in which the family says: "We have no problems."

"Avoidance" refers to a situation in which conflict begins to emerge but is stopped, covered up, or inhibited in some way that prevents it from emerging. Examples of avoidance include postponing ("Let's not have a fight now."), humor ("You're so cute when you're mad."), minimizing ("That's not really important."), and inhibiting ("Let's not argue; you know what can happen.").

"Diffusion" refers to situations in which conflict begins to emerge, but discussion about the conflict is diverted in another direction. This diversion prevents conflict resolution by distracting the family's attention away from the original conflict. This change of subject is often framed as a personal attack against the person who raised the original issue. For example, a mother says to her husband, "I don't like it when you get home late," but the husband changes the topic by responding: "What kind of mother are you anyway, letting your son stay home from school today when he is not even sick!"

"Conflict emergence" without resolution occurs when different opinions are clearly expressed, but no final solution is accepted. Everyone knows exactly where everyone else stands, but little is done to reach a negotiated agreement. Sometimes this occurs because the family, while willing to discuss the problem, simply does not know how to negotiate a compromise.

Emergence of the conflict and its resolution is generally considered to be the best outcome. Separate accounts and opinions regarding a particular conflict are clearly expressed and confronted. Then, the family is able to negotiate a solution that is acceptable to all family members involved.

In some cases, conflicts need to be postponed for more appropriate times. For example, if a family member is very angry, tired, or sick, it may be reasonable to table the conflict until he or she is ready to have a meaningful discussion. However, in such instances, it is critical that the family set a specific time to address the conflict. Indefinitely postponing conflict resolution is a sign of avoidance. A postponement for a definite amount of time is adaptive. 


\section{Chapter 3 Diagnosing Family System Problems}

In other instances, a person may decide that the issue at hand is not worth having an argument about. For example, one person may want to stay home while his or her partner wants to go dancing. Either partner may opt to compromise by agreeing to the other's preference. So long as partners take turns compromising, this is adaptive and balanced. However, if the same person is always the one to give in, this may reflect the use of denial by one partner to avoid conflict with the other. 


\section{Chapter 4 Orchestrating Change}

This chapter describes the BSFT approach to orchestrating change in the family. The first section describes how BSFT counselors establish a therapeutic relationship, including the importance of joining with the family, the role of tracking family interactions, and what is involved in building a treatment plan. The second section describes strategies for producing change in the family, including focusing on the present, reframing negativity in the family, shifting patterns of interaction through reversals of usual behavior, changing family boundaries and alliances, "detriangulating" family members caught in the middle of others' conflicts, and opening up closed family systems or subsystems by directing new interactions.

\section{Establishing a Therapeutic Relationship}

The counselor's first step in working with a family is to establish a therapeutic relationship with the family, beginning with the very first contact with family members. The quality of the relationship between the counselor and the family is a strong predictor of whether families will come to, stay in, and improve in treatment (Robbins et al. 1998). In general, studies have found that the therapeutic relationship is a strong predictor of success in many forms of therapy (Rector et al. 1999; Stiles et al. 1998). Validating and supporting the family as a system and attending to each individual family member's experience are particularly important aspects of developing and maintaining a good therapeutic relationship (Diamond et al. 1999; Diamond and Liddle 1996).

Establishing a therapeutic relationship means that the BSFT counselor needs to form a new system - a therapeutic system-made up of the counselor and the family. In this therapeutic system, the counselor is both a member and its leader. One challenge for the BSFT counselor is to establish relationships with all family members, some of whom are likely to be in conflict with each other. For example, drug-abusing adolescents generally begin treatment in conflict with their parent(s) or guardian(s). Both parties approach counseling needing support from the counselor. The counselor's job is to find ways to support the individuals on either side of the conflict. For example, the counselor might say to the adolescent, "I am here to help you explain to your parents that regular school is not for you, that you are interested in trade school." To the parent, the counselor might say, "I am here to help you keep your son off drugs." By offering each family member 
something he or she would like to achieve, the counselor is able to establish a therapeutic alliance with the whole family.

The BSFT approach is based on the view that building a good therapeutic relationship is necessary to bring about change in the family. Several strategies for building a therapeutic relationship, joining, tracking, and building a treatment plan, are discussed below.

\section{Joining}

A number of techniques can be used to establish a therapeutic relationship. Some of these techniques fall into the category of "joining," or becoming a temporary member of the family.

\section{Definition of Joining}

In BSFT, joining has two aspects. Joining it is the steps a counselor takes to prepare the family for change. Joining also occurs when a therapist gains a position of leadership within the family. Counselors use a number of techniques to prepare the family to accept therapy and to accept the therapist as a leader of change. Some techniques that the therapist can use to facilitate the family's readiness for therapy include presenting oneself as an ally, appealing to family members with the greatest dominance over the family unit, and attempting to fit in with the family by adopting the family's manner of speaking and behaving. A counselor has joined a family when he or she has been accepted as a "special temporary member" of the family for the purpose of treatment. Joining occurs when the therapist has gained the family's trust and has blended with family members. To prepare the family for change and earn a position of leadership, the counselor must show respect and support for each family member and, in turn, earn each one's trust.

One of the most useful strategies a counselor can employ in joining is to support the existing family power structure. The BSFT counselor supports those family members who are in power by showing respect for them. This is done because they are the ones with the power to accept the counselor into the family; they have the power to place the counselor in a leadership role, and they have the power to take the family out of counseling. In most families, the most powerful member needs to agree to a change in the family, including changing himself or herself. For that reason, the counselor's strongest alliance must initially be with the most powerful family member. BSFT counselors must be careful not to defy those in power too early in the process of establishing a therapeutic relationship. Inexperienced family counselors often take the side of one family member against another, behaving as though one were right and the other were obviously wrong. In establishing relationships with the family, the counselor must join all family members, not just those with whom he or she agrees. In fact, frequently, the person with whom it is most critical to establish an alliance or bond is the most powerful and unlikable family member.

Many counselors in the drug abuse field feel somewhat hopeless about helping the families of drug-abusing youths because these 
families have many serious problems. Counselors who feel this way may find a discussion about becoming a member of the family unhelpful because their previous efforts to change families have been unsuccessful. BSFT teaches counselors how to succeed by approaching families as insiders, not as outsiders. As outsiders, counselors typically attempt to force change on the family, often through confrontation. However, the counselor who has learned how to become part of the system and to work with families from the inside should seldom need to be confrontational. Confrontation erodes the rapport and trust that the counselor has worked hard to earn. Confrontation can change the family's perception of the counselor as being an integral part of the therapeutic system to being an outsider.

\section{The Price of Failed Joining}

An example may help illustrate what is meant by powerful family members. The court system referred a family to counseling because its oldest child had behavior problems. The mother was willing to come to counseling with her son, but the mother's live-in boyfriend did not want the family to be in counseling. The counselor advised the mother to come to therapy with the adolescent anyway. The boyfriend felt that his position of power had been threatened by the potential alliance between the mother and the counselor. As a result, the boyfriend reasserted himself, demanding that she stop participating in counseling. She then dropped out of counseling. This is clearly a case in which the counselor's early challenge of the family's way of "operating" caused the entire family to drop out of treatment. The counselor could and should have been more aware and respectful of the family's existing power structure. Respect, in this case, does not mean that the counselor approves of or agrees with the boyfriend's behavior. Rather, it means that the counselor understands how this family is organized and works his or her way into the family through the existing structure.

A more adaptive counseling strategy might be to call the mother's boyfriend, with the mother's permission, to recognize his position of power in the family and request his help with his girlfriend's son.

\section{A Cautionary Note: Family Secrets}

As was already stated, joining is about establishing a relationship with every member of the family. Sometimes a family member will try to sabotage the joining process by using family secrets. Some secrets can cause the counselor such serious problems that he or she is forced to refer the family he or she had intended to help to another counselor. Secrets are best dealt with up front. The counselor should not allow himself or herself to get trapped in a special relationship with one family member that is based on sharing a secret that the other family members do not know. A counselor who keeps a secret is caught between family members. The counselor has formed an alliance with one family member to the exclusion of others. In some cases, it is not just an alliance with one family member but also an 
alliance with one family member against another family member. It means that the family member with the secret can blackmail the counselor with the threat of revealing that the counselor knows this secret and didn't address it with the family. Consequently, a family secret is a very effective strategy that family members can use to sabotage the treatment, if counselors let them.

For these reasons, counselors should make it a rule to announce to each family at the onset of counseling that he or she will not keep secrets. The counselor should also say that if anyone shares special information with the counselor, the counselor will help them share it with the appropriate people in the family. For example, if a wife calls and tells the counselor that she is having an affair, her spouse will need to know, although the children do not need to know the parents' marital issues. In this case, the counselor would say, "This affair is indicative of a problem in your marriage. Let me help you share it with your husband." The counselor must do whatever is needed to continue to help the wife see that affairs are symptoms of marital problems. The affair can be reframed as a cry for help, a call for action, or a basic discontent. If so, these marital issues or problems need to be discussed.

It is possible that despite all the counselor's efforts, the wife will respond with an absolute, "No, I don't want to tell him. He would leave me. Besides, this affair doesn't mean all that much." Typically BSFT therapy only gets into marital issues to the extent that the marital problems are interfering with the parents' abilities to function effectively as parents. However, the counselor has no choice but to help the wife tell her husband about the affair. If the wife absolutely refuses, then the counselor has lost his or her bid for leadership in the counseling process. The wife now has control over the counseling process. For that reason, the counselor must refer the family to another counselor.

\section{Tracking}

In the example on p. 27 about the mother's powerful boyfriend, it was recommended that the counselor use the way in which the family is organized, or interacts, with the father figure in a position of power, as a vehicle for getting the family into treatment. This strategy in which the counselor learns how the family interacts and then uses this information to establish a therapeutic plan of action is called "tracking." Tracking is a technique in which the counselor respects

how the family interacts but, at the same time, takes advantage of those family interactions for therapeutic purposes. Sometimes families interact spontaneously, permitting the counselor to observe the family dynamics. When this does not happen spontaneously, the counselor must encourage the family to interact.

\section{Encouraging the Family to Interact}

When a family is in counseling, family members like to tell the counselor stories about each other. For example, a mother might say to the counselor, "My son did so and so." In contrast to the way in which the counselor functions in other therapy models, the BSFT 
counselor is not interested in the content of the family members' stories. Instead, the counselor is interested in observing (and correcting) problematic interactions. To observe the family's patterns of interaction, the counselor must ask family members to talk directly to each other about the problem. When this occurs, the counselor can observe or track what happens when the family members discuss the issue. The counselor can then watch the family's interactions: fighting, disagreeing, and struggling with their issues. By tracking, the counselor will not only be able to identify the interactive patterns in the family, but also will be able to determine which of these patterns may be causing the family's problems or symptoms. The added benefit of this kind of tracking is that the counselor shows respect for the family's ways of interacting.

\section{Tracking Content and Process}

The difference between "content" and "process" was discussed in Chapter 2 (see p. 13). Content is the subject matter that is being discussed. Process refers to the interactions that underlie the communication. By observing the process, the counselor learns who is dominant, who is submissive, what emotions are expressed in the interaction, and the unwritten rules that appear to guide the family's communication and organization. For example, a mother may mention that her son's drug problem is a concern. The grandmother responds by shouting that the mother is overreacting and needs to back off. The content of the interaction - the son's drug problem-is not nearly as important as the process being displayed-the grandmother undermining the mother and shutting her down. Often the counselor will track or use the family's content because it represents a topic that is important to the family. In this example, the counselor might keep the focus of the counseling session on the son's drug problem because it is an important topic in this family. However, the focus of BSFT is entirely on changing process. What needs to be changed here, as a first step, is the parent figures' inability to agree on the existence of a problem, and, more generally, the grandmother's tendency to invalidate the mother's concerns.

\section{Mimesis}

"Mimesis" is a form of tracking for the purpose of joining. It refers to mimicking the family's behavior in an effort to join with the family. Mimesis can be used to join with the whole family. For example, a counselor can act jovial with a jovial family. Mimesis also can be used to join with one family member. Mimesis is used in everyday social situations. For example, by attending to how others dress for a particular activity so that one can dress appropriately, one is attempting to gain and demonstrate acceptance by mimicking the type of dress that is worn by others (e.g., casual). People mimic other people's moods when they act like the other people do in certain situations. For example, at a funeral they would act sad as others do and at a celebration they would act joyful. When the counselor validates a family by mimicking its behavior, family members are more likely to accept the counselor as one of their own. 


\section{Building a Treatment Plan}

Mimesis also refers to using a family's own ways of speaking to join with the family. Each family and each family member has its, his, or her own vocabulary and perspective. For instance, if a family member is a carpenter, it might be useful to use the language of carpentry. The therapist might say, "Dealing with your son requires lots of different tools, just like jobs at work do. Sometimes you need to use a hammer and use a lot of force, and sometimes you need to use a soft cloth for a more gentle job." If a family member is an accountant, it may be helpful to speak in terms of assets and liabilities. If a person is religious, it may be helpful to speak of God's will.

Whatever language a family uses should be the language the counselor uses to converse with that family. The counselor should not talk to a family using vocabulary that is found in this manual-words such as "interactions," "restructuring," and "systems." Instead, the BSFT counselor should use the "pots and pans" language that each of the family members uses in his or her everyday life. For example, if families are uncomfortable with the term "counseling," the term "meetings" might be used.

Much of the work the counselor does to establish the therapeutic relationship involves learning how the family interacts to better blend with the family. However, the counselor cannot learn the ways in which the family interacts unless he or she sees family members interacting as they would when the counselor is not present. Getting family members to interact can be difficult because families often come into counseling thinking that their job is to tell the counselor what happened. Therefore, it is essential that counselors decentralize themselves by discouraging communications that are directed at them, and instead encouraging family members to interact so that they can be observed behaving in their usual way.

BSFT diagnoses are made to identify adaptive and maladaptive patterns of family interaction so that the counselor can plan practical, strategically efficient interventions. The purpose of the intervention is to improve the family interactions most closely linked to the adolescent's symptoms. This, in turn, will help the family to manage those symptoms.

\section{Enactment: Identifying Maladaptive Interactions}

In BSFT, the counselor assesses and diagnoses the family's interactions by allowing the family to interact in the counseling session as it normally does at home. To begin, the counselor asks the family to discuss something. When a family member speaks to the counselor about another family member who is present, the counselor asks the family member who is speaking to repeat what was said directly to the family member about whom it was said. Family interactions that occur as they would at home and that show the family's typical interactional patterns are called "enactments." An enactment can either occur spontaneously, or the counselor can initiate it by asking family members to discuss something among themselves. Creating enactments of family 
interactions is like placing the counselor on the viewing side of a oneway mirror and letting the family "do its thing" while the counselor observes.

Different therapy models have different explanations for why a family or adolescent is having difficulty, and so they have different targets of intervention. BSFT targets interactional patterns. Because BSFT is a problem-focused therapy approach, it targets those interactional patterns that are most directly related to the symptom for which the family is seeking treatment. Targeting patterns most directly related to the symptom allows BSFT to be brief and strengthens a therapist's relationship with a family by demonstrating that the therapist will help the family solve the problems family members have identified.

Families that develop symptoms tend to be organized or to function around those symptoms. That's because a symptom works like a magnet, organizing the family around it. This is especially true if the symptom is a serious, life-threatening one, such as drug abuse. Therefore, it is most efficient to work with the family by focusing on the symptom around which the family has already organized itself.

\section{Family Crises as Enactments}

Enactments are used to observe family interactions in the present and to identify family interactional problems. Family crises are particularly opportune types of enactments because they are highly charged, and family members are emotionally available to try new behaviors. Therefore, families in crisis should be seen immediately. In addition to gaining valuable information about problematic family interactions, the counselor gains considerable rapport with families because he or she is willing to be of service at a time of great need.

\section{A Cautionary Note: Adolescents Attending Therapy Sessions on Drugs}

Counselors usually refuse to work with a client who comes into the therapy session on drugs because the client is viewed as "not being all there" to do the treatment work. However, in the case of a family therapy such as BSFT, determining whether to conduct the session is a strategic decision the counselor must make. One possibility in BSFT is to view the adolescent on drugs as an enactment of what the family confronts at home all the time. Thus, when an adolescent comes to therapy on drugs, it can be viewed as an opportunity for the counselor to teach the family how to respond to the adolescent when he or she takes drugs. The BSFT counselor can see how each family member responds to this situation and look for the maladaptive interactions that allow the adolescent to continue this behavior. The counselor can then work with the non-drug-using family members to change their usual way of responding to the adolescent on drugs. Hence, the work in this session is not with the adolescent but with the other family members. 


\section{From Diagnosis to Planning}

Once a therapeutic relationship has been established and a diagnosis has been formulated, the counselor is ready to develop a treatment plan. The treatment plan lays out the interventions that will be necessary to change those family maladaptive interactional patterns that have been identified as related to the presenting symptom. Problematic patterns of family interaction are diagnosed using the six dimensions of family interaction discussed in Chapter 3 (organization, resonance, developmental stages, life context, identified patient, and conflict resolution). Often some dimensions are more problematic than others. The interventions need to focus more on the most problematic interactions than on the others.

The six dimensions of the family's interactions operate in an interdependent fashion. For this reason, it may not be necessary to plan a separate intervention to address each problem that has been diagnosed. For example, addressing a family's tendency to blame its problems on the adolescent (i.e., the identified patient) may bring the family's ineffective conflict resolution strategies to light. In a similar fashion, addressing a son's role as his mother's confidant (i.e., inappropriate developmental stage) may bring out the rigid and inflexible boundary between the parent figures.

\section{Producing Change}

As was stated earlier, the focus of BSFT is to shift the family from maladaptive patterns of interaction to adaptive ones. Counselors can use a number of techniques to facilitate this shift. These techniques, all of which are used to encourage family members to behave differently, fall under the heading of "restructuring." In restructuring, the counselor orchestrates and directs change in the family's patterns of interaction (i.e., structure). Some of the most frequently used restructuring techniques are described in this chapter.

When the family's structure has been shifted from maladaptive toward adaptive, the family develops a mastery of communication and management skills. In turn, this mastery will help them solve both present and future problems. To help family members master these skills, the BSFT counselor works with them to develop new behaviors and use these new behaviors to interact more constructively with one another. After these more adaptive behaviors and interactions occur, the BSFT counselor validates them with positive reinforcements. Subsequently, the counselor gives the family the task of practicing these new behaviors/interactions in naturally occurring situations (e.g., when setting a curfew or when eating meals together) so that family members can practice mastering these skills at home.

Mastering more adaptive interactions provides families with the tools they need to manage the adolescent's drug abuse and related problem behaviors. Some adaptive behaviors/interactions that validate individual 
family members are self-reinforcing. However, the counselor needs to reinforce those behaviors/interactions that initially are not strongly self-reinforcing (i.e., validated) to better ensure their sustainability. As family members reinforce each other's more adaptive skills, they master the skills needed to behave in adaptive ways. It is very important to note that mastery of adaptive skills is not achieved by criticizing, interpreting, or belittling the individual. Rather, it is achieved by incrementally shaping positive behavior.

The rest of this chapter describes seven frequently used restructuring techniques (i.e., to change families' patterns of interaction). These techniques will give a counselor the basic tools needed to help a family change its patterns of interaction. The seven restructuring techniques are:

- Working in the present

- Reframing negativity

- Reversals

- Working with boundaries and alliances

- Detriangulation

- Opening up closed systems

- Tasks

\section{Working in the Present}

Although some types of counseling focus on the past (Bergin and Garfield 1994), BSFT focuses strictly on the present. In BSFT, families do not simply talk about their problems, because talking about problems usually involves telling a story about the past. Working in the present with family interactional processes that are maintaining the family's symptoms is necessary to bring about change in BSFT. Consequently, the BSFT counselor wants the family to engage in interactions within the therapy session-in the same way that it would at home. When this happens and family members enact the way in which they interact routinely, the counselor can respond to help the family members reshape their behavior. Several techniques that require working in the present with family processes are found in subsequent sections within this chapter.

\section{Does BSFT Ever Work in the Past?}

Counselors work with the past less than 5 percent of the counseling time. One important example of working in the past can be illustrated by an early counseling session in which the parent and adolescent are in adversarial roles. The parent may be angry or deeply hurt by the youth's behavior. One strategy to overcome this impasse in which neither family member is willing to bend is to ask the parent, "Can you remember when Felix was born? How did you feel?" The parent may say nostalgically: "He was such a beautiful child. The minute I saw him, I was enchanted. I loved him so much I thought my heart would burst." 


\section{Reframing: Systemic Cognitive Restructuring}

This kind of intervention is called "reconnection" (cf. Liddle 1994, 1995, 2000). When the parent is hardened by the very difficult experiences he or she has had with a troublesome adolescent, counselors sometimes use the strategy of reconnection to overcome the impasse in which neither the parent nor the youth is willing to bend first. Reconnection is an intervention that helps the parent recall the positive feeling (love) that he or she once had for the child. After the parent expresses his or her early love for the child, the counselor turns to the youth and says: "Did you know your mother loves you so very much? Look at the expression of bliss on her face."

As can be seen, the counseling session digressed into the past for a very short time to reconnect the parent. This was necessary to change the here-and-now interaction between two family members. The reconnection allowed the counselor to transform an interaction characterized by resentment into an interaction characterized by affection. Because the feelings of affection and bonding do not last long, the counselor must move quickly to use reconnection as a bridge that moves the counseling to a more positive interactional terrain.

To "reframe," a counselor creates a different perspective or "frame" of reality than the one within which the family has been operating. He or she presents this new frame to the family in a convincing manner-that is, "selling" it to the family and then using this new frame to facilitate change. The purpose of systems-oriented, cognitive restructuring (reframing) is to change perceptions and/or meaning in ways that will enable family members to change their interactions. Most of the time, in families of adolescent drug abusers, negativity needs to be reframed. Negativity is usually exhibited as blaming, pejorative, and invalidating statements ("You are no good." "I can't trust you."), and, in general, "angry fighting." Reframing negativity might involve describing a mother's criticism of her teenage son as her desire that he be successful, or reframing fighting as an attempt to have some sort of connection with another family member.

It has been suggested that "... high levels of negativity interfere with effective problem-solving and communication within the family" (Robbins et al. 1998, p. 174). Robbins and colleagues report that negativity in family therapy sessions is linked to dropping out of family therapy. For those who remain in therapy, negativity is linked to poor family therapy outcomes. Because negativity is bad for the family and for the therapy, most contemporary family therapies target negativity (Alexander et al. 1994). The best-known strategy for transforming negative interactions into positive ones is reframing (Robbins et al. 2000).

While the counselor is encouraged to permit family members to interact with each other in their usual way and to join before orchestrating change, a caveat is necessary when intense negative feelings accompany conflictive interactions. If the family is to remain in counseling, family members must experience some relief from the negative feelings soon after counseling begins. Therefore, counselors are encouraged 
to use reframing abundantly, if necessary, in the first and perhaps the first few sessions to alleviate the family's intensive negative feelings. Such reframes also may allow family members to discuss their pain and grievances in a meaningful way.

An example will help illustrate the use of reframing negative feelings to create more positive feelings among family members. Anger is a fairly common emotion among families with an adolescent who is involved in antisocial activities. The parents may feel angry that their attempts to guide their child down the "right" path have failed and that the child disrespects their guidance. The adolescent is likely to interpret this anger as uncaring and rejecting. Both parties may feel that the other is an adversary, which severely diminishes the possibility that they can have a genuine dialogue.

The particular reframe that needs to be used is one that changes the emotions from anger, hurt, and fighting (negative) to caring and concern (positive). The counselor must create a more positive reality or frame. The counselor, for example, might say to the parent, "I can see how terribly worried you are about your son. I know you care an awful lot about him, and that is why you are so frustrated about what he is doing to himself."

With this intervention, the counselor helps move both the parent's and the child's perceptions from anger to concern. Typically, most parents would respond by saying, "I am very worried. I want my child to do well and to be successful in life." When the youth hears the parent's concern, he or she may begin to feel less rejected. Instead of rejecting, the parent is now communicating concern, care, and support for the child. Hence, by creating a more positive sense of reality, the counselor transforms an adversarial relationship between the parent(s) and the adolescent, orchestrating opportunities for new channels of communication to emerge and for new interactions to take place between them.

Reframing is among the safest interventions in BSFT, and, consequently, the beginning counselor is encouraged to use it abundantly. Reframing is an intervention that usually does not cause the counselor any loss of rapport. For that reason, the counselor should feel free to use it abundantly, particularly in the most explosive situations.

\section{Affect: Creating Opportunities for New Ways of Behaving}

In BSFT, counselors are interested in affect (a feeling or an emotion) as it is reflected in interactions. In BSFT, the counseling strategy is to use emotion as an opportunity to "move" the family to a new, more adaptive set of interactions. One of many possible ways of working with emotion is found in the following example. When a mother cries, the counselor might suggest to the drug-abusing youngster, "Ask your mom to tell you about her tears." An alternative would be, "What do you think your mom's tears are trying to say?" If the youth responds, "I think it is...," the counselor would follow with a directive 
to the youth, "Ask your mother if what you think her tears mean is why she is crying." In this way, the crying is used to initiate an interaction among family members that acknowledges not only the emotion in crying but also the experience underlying the crying. In other words, the crying is used to promote interactions that show respect for the emotion as well as promote a deeper level of understanding among family members.

In another example, a drug-abusing adolescent and her family come to their first BSFT counseling session. The parents proceed to describe their daughter as disobedient, rebellious, and disrespectfula girl who is ruining her life and going nowhere. They are angry and reject this young girl, and they blame her for all the pain in the family. In this instance, the BSFT counselor recognizes that the family is "stuck" about what to do with this girl and that their inability to decide what to do is based on the view they have developed about her and her behavior. To "open up" the family to try new ways to reach the youngster, the BSFT counselor must present a new "frame" or perspective that will enable the family to react differently toward the girl. The BSFT counselor might tell the family that, although she realizes how frustrated and exasperated they must feel about their daughter's behavior, "it is my professional opinion that the main problem with this girl is that she is very depressed and is in a lot of pain that she does not know how to handle." Reframing is a practical tool used to stimulate a change in family interactions. With this new frame, the family may now be able to behave in new ways toward the adolescent, which can include communicating in a caring and nurturing manner. A more collaborative set of relationships within the family will make it easier for the parents to discuss the daughter's drug abuse, to address the issues that may be driving her to abuse drugs, and to develop a family strategy to help the adolescent reduce her drug use.

\section{Reversals}

When using the technique called "reversal," the counselor changes a habitual pattern of interacting by coaching one member of the family to do or say the opposite of what he or she usually would. Reversing the established interactional pattern breaks up previously rigid patterns of interacting that give rise to and maintain symptoms, while allowing alternatives to emerge. If an adolescent gets angry because her father nagged her, she yells at her father, and the father and daughter begin to fight, a reversal would entail coaching the father to respond differently to his daughter by saying, "Rachel, I love you when you get angry like that," or "Rachel, I get very frightened when you get angry like that." Reversals make family members interact differently than they did when the family got into trouble.

\footnotetext{
Working With Boundaries and Alliances

Certain alliances are likely to be adaptive. For example, when the authority or parent figures in the family are allied with each other, they will be in a better position to manage the adolescent's problem behaviors. However, when an alliance forms between a parent figure and one of the children against another parent figure, the family is
} 
likely to experience trouble, especially with antisocial adolescent behavoir. An adolescent who is allied with an authority figure has a great deal of power and authority within the family system. Therefore, it would be difficult to place limits on this adolescent's problem behavior. One goal of BSFT is to realign maladaptive alliances.

One important determinant of alliances between family members is the psychological barrier between them, or the metaphorical fence that distinguishes one member from another. BSFT counselors call this barrier or fence a "boundary." Counselors aim to have clear boundaries between family members so that there is some privacy and some independence from other family members. However, these should not be rigid boundaries, with which family members would have few shared experiences. By shifting boundaries, BSFT counselors change maladaptive alliances across the generations (e.g., between parent figures and child). For example, in a family in which the mother and the daughter are allied and support each other on almost all issues while excluding the father, the mother may no longer be powerful enough to control her daughter when she becomes an adolescent and may need help. In this case, an alliance between the mother and the father needs to be re-established, while the cross-generational coalition between mother and daughter needs to be eliminated.

It is the BSFT counselor's job to shift the alliances that exist in the family. This means restoring the balance of power to the parents or parent figures so that they can effectively exercise their leadership in the family and control their daughter's behavior. The counselor attempts to achieve these alliance shifts in a very smooth, subtle, and perhaps even sly fashion. Rather than directly confronting the alliance of the mother and daughter, for example, the counselor may begin by encouraging the father to establish some form of interaction with his daughter.

Boundary shifting is accomplished in two ways. Some boundaries need to be loosened, while others need to be strengthened. Loosening boundaries brings disengaged family members (e.g., father and daughter) closer together. This may involve finding areas of common interest between them and encouraging them to pursue these interests together. For instance, in the case of a teenaged son enmeshed with his mother and disengaged from his father, the counselor may direct the father to involve his son in a project or to take his son on regular outings. The counselor also may arrange the seating in counseling sessions to help strengthen some alliances and loosen others.

In addition to bringing family members closer together, the counselor may need to strengthen the boundaries between enmeshed family members to create more separation. One example is the mothergrandmother parenting system in which the grandmother enables her 
grandson's drug use by protecting him from his mother's attempts to set limits. Rather than confronting the grandmother-adolescent alliance directly, the counselor may first encourage the mother and grandmother to sit down together and design a set of rules and responsibilities for the adolescent. This process of designing rules often requires the parent figures to work out some of the unresolved conflict(s) in their relationship, without the counselor having to address that relationship directly. This brings the mother closer to the grandmother and distances the grandmother from the adolescent, thereby rearranging the family's maladaptive hierarchy and subsystem composition.

It should be noted that, in this case, the counselor tracks the family's content (grandmother hiding adolescent's drug use from mother) as a maneuver to change the nature of the interaction between the mother and the grandmother from an adversarial relationship to one in which they agree on something. The adolescent's drug use provides the content necessary to strengthen the boundaries between the generations and to loosen the boundaries between the parent figures.

Clearly, bringing the mother and grandmother together to the negotiating table is only an intermediate step. After that, the tough work of helping mother and grandmother negotiate their deep-seated resentments and grievances against each other begins. Because the counselor follows a problem-focused approach, he or she does not attempt to resolve all of the problems the parent figures encounter. Instead, the counselor tries to resolve only those aspects of their difficulties with each other that interfere with their ability to resolve the problems they have with the adolescent in the family.

\section{Behavioral Contracting as a Strategy for Setting Limits for Both Parent and Adolescent}

From a process perspective, setting clear rules and consequences helps develop the demarcation of boundaries between parent(s) and child(ren). Sometimes when a parent and an adolescent have a very intense conflictive relationship in which there is a constant battle over the violation of rules, the rules and their consequences are vague, and there is considerable lack of consistency in their application. In these cases, it is recommended that the counselor use behavioral contracting to help the parent(s) and the adolescent agree on a set of rules and the resulting consequences if he or she fails to follow these rules. The counselor encourages the parent(s) and the adolescent to negotiate a set of clearly stated and enforceable rules, and encourages both parties to commit to maintaining and following these rules.

Helping parents use behavioral contracting to establish boundaries for themselves in relationship to their adolescent is of tremendous therapeutic value. Parents who have established boundaries can no longer respond to the adolescent's behavior/misbehavior according to how they feel at the time (lax, tired, frustrated, angry). The parents have committed themselves to respond according to agreed-upon 
rules. From a BSFT point of view, it is very important for the counselor to begin to help the parents develop adequate boundaries with their adolescent children who have behavior problems.

In families that have problems with boundaries, the counselor's most difficult task is to get the parents to stick to their part of the contract. Counselors expect that the adolescent will not keep his or her part of the contract and instead will try to test whether his or her parents will try to stick to their part of the contract. When the adolescent misbehaves, parents tend to behave in their usual way, which may be a reaction to the way they feel at the moment. The counselor's job is to make the parents uphold their side of the agreement. Once parents have set effective boundaries with their adolescent children, most misbehavior quickly diminishes. (Of course, sometimes rules and consequences need to be renegotiated as parents and adolescents begin to acquire experience with the notion of enforceable rules and consequences.)

\section{Boundaries Between the Family and the Outside World}

It is important not only to understand the nature of the alliances and boundaries that occur within the family but also to understand the boundaries that exist between the family and the outside world. (See Chapter 3, p. 21 on life context.)

Some families have very rigid boundaries around themselves, prohibiting their members from interacting with the outside world. Other families have very weak boundaries around themselves that allow outsiders to have an undue influence on family members. Either of these extremes can be problematic and is fair ground for BSFT intervention. For example, if parents are uninvolved with their children's school or friends (rigid boundaries), the BSFT counselor works to get the parents to participate more fully in their child's school life and to interact more with their child's friends.

\section{Detriangulation}

As was said earlier, triangles occur when a third, usually less powerful, person gets involved in a conflict between two others. It is a basic assumption of BSFT that the only way conflict between two people (called a "dyad") can be resolved is by keeping the conflict between them. Bringing in a third person and forming a triangle becomes an obstacle to resolving the conflict. The third person usually is drawn into a coalition with one of the parties in conflict and against the other. This coalition results in an imbalance within the original dyad. The issues involved in the conflict are detoured through the third person rather than dealt with directly. For example, when parent A has a fight with parent B, parent B may attack the adolescent in retaliation for parent A's behavior (or attempt to enlist the youth's support for his or her side of the argument) rather than expressing his or her anger directly to parent A. Such triangulated adolescents are often blamed for the family's problems, and they may become identified patients and develop symptoms such as drug abuse. 
Because triangulation prevents the involved parties from resolving their conflicts, the goal of counseling is to break up the triangle. Detriangulation permits the parents in conflict to discuss issues and feelings directly and more effectively. Detriangulation also frees the third party, the adolescent, from being used as the escape valve for the parents' problems.

One of the ways in which a BSFT counselor achieves detriangulation is by keeping the third party (i.e., the adolescent) from participating in the discussions between the dyad. Another way to set boundaries to detriangulate is to ask the third party not to attend a therapy session so that the two conflicting parties can work on their issues directly. For example, when working with a family in which the son begins to act disrespectfully whenever his parents begin to argue, the counselor might instruct the parents to ignore the son and continue their discussion. If the son's misbehavior becomes unmanageable, the counselor may ask the son to leave the room so that the parents can argue without the son's interference. Eventually, the counselor will ask the parents to collaborate in controlling the son.

\section{Attempts by the Family to Triangulate the Counselor}

Triangulation does not necessarily have to involve only family members. Sometimes a counselor can become part of a triangle as well. One of the most common strategies used by family members is to attempt to get the counselor to ally himself or herself with one family member against another. For example, one family member might say to the counselor, "Isn't it true that I am right and he is wrong?" "You know best, you tell him." "We were having this argument last night, and I told her that you had said that...."

Triangulation is always a form of conflict avoidance. Regardless of whether it is the counselor or a family member who is being triangulated, triangulation prevents two family members in conflict from reaching a resolution. The only way two family members can resolve their conflicts is on a one-to-one basis.

An important reason why the counselor does not want to be triangulated is that the person in the middle of a triangle is either rendered powerless or symptomatic. In the case of the counselor, the "symptom" he or she would develop would be ineffectiveness as a therapist, that is an inability to do his or her job well because his or her freedom of movement (e.g., changing alliances, choosing whom to address, etc.) has been restricted. A triangulated counselor is defeated. If the counselor is unable to get out of the triangle, he or she has no hope of being effective, regardless of what else he or she does or says.

When a family member attempts to triangulate the counselor, the counselor has to bring the conflict back to the people who are involved in it. For example, the counselor might say, "Ultimately, it doesn't matter what I think. What matters is what the two of you agree to, together. I am here to help you talk, negotiate, hear each 


\section{Opening Up Closed Systems}

\section{Tasks}

\section{Central Role}

The use of "tasks" or assignments is central to all work with families. The counselor uses tasks both inside and outside the counseling sessions as the basic tool for orchestrating change. Because the emphasis in BSFT is in promoting new skills among family members, at both the level of individual behaviors and in family interactional relations, tasks serve as the vehicle through which counselors choreograph opportunities for the family to behave differently.

In the example in which mother and son were initially allied and the father was left outside of this alliance, father and son were first assigned the task of doing something together that would interest them both. Later on, the mother and father were assigned the collaborative task of working together to define rules regarding the types of behaviors they would permit in their son and the consequences that they would assign to their son's behavior and misbehavior.

\section{General Rule}

It is a general rule that the BSFT counselor must first assign a task for the family to perform in the therapy session so that the counselor has an opportunity to observe and help the family successfully carry out the task. Only after a task has been accomplished successfully in the therapy session can a similar followup task be assigned to the family to be completed outside of therapy.

Moreover, the counselor's aim is to provide the family with a successful experience. Thus, the counselor should try to assign tasks that are sufficiently doable at each step of the counseling process. The counselor should start with easy tasks and work up to more difficult 
ones, slowly building a foundation of successes with the family before attempting truly difficult restructuring moves.

\section{Hope for the Best; Be Prepared for the Worst}

Counselors should never expect the family to accomplish the assigned tasks flawlessly. In fact, if family members were skillful enough to accomplish all assigned tasks successfully, they would not need to be in counseling. When tasks are assigned, counselors should always hope for the best but be prepared for the worst. After all, a task represents a new way of behaving for the family and one that may be difficult given that they have had years of practice engaging in the old ways of behaving.

As the family attempts to carry out a task, the counselor should help the family overcome obstacles it may encounter. However, in spite of the counselor's best efforts, the task is not always accomplished. The counselor's job is to observe and/or uncover what happened and identify the obstacles that prevented the family from achieving the task. When a task fails, the counselor starts over and works to overcome the newly identified obstacles. Unsuccessful attempts to complete tasks are a great source of new and important information regarding the interactions that prevent a family from functioning optimally.

The first task that family counselors give to all of their cases is to bring everyone into the counseling session. Every counselor who works with problem youths and their families knows very well that most of the families who need counseling never reach the first counseling session. Therefore, these families can be described as having failed the first task given them, to come in for counseling. This task, called engagement, is so important that we have devoted the next chapter to it. 


\section{Chapter 5 Engaging the Family Into Treatment}

Previous chapters have described the basic concepts of BSFT, how to assess and diagnose maladaptive interactions and their relationship to symptoms, and the intervention strategies characteristic of this approach. These concepts also are the building blocks for the techniques that are used to engage resistant families into counseling.

This chapter defines, in systems terms, the nature of the problem of resistance to treatment and redefines the nature of BSFT joining, diagnosing, and restructuring interventions in ways that take into account those patterns of interaction that prevent families from entering treatment.

\section{The Problem}

Regardless of their professional orientation and where or how they practice, all counselors have had the disappointing and frustrating experience of encountering "resistance to counseling" in the form of missed or cancelled first appointments. For BSFT counselors, this becomes an even more common and complex issue because more than one individual needs to be engaged to come to treatment.

Unfortunately, some counselors handle engagement problems by accepting the resistance of some family members. In effect, the counselor agrees with the family's assessment that only one member is sick and needs treatment. Consequently, the initially well-intentioned counselor agrees to see only one or two family members for treatment. This usually results in the adolescent and an overburdened mother following through with counseling visits. Therefore, the counselor has been co-opted into the family's dysfunctional process.

Not only has the counselor "bought" the family's definition of the problem, but he or she also has accepted the family's ideas about who is the identified patient. When the counselor agrees to see only one or two family members, instead of challenging the maladaptive family interaction patterns that kept the other members away, he or she is reinforcing those family patterns. In the example in which a mother and son are allied against the father, if the counselor accepts 
the mother and son into counseling, he or she is reinforcing the father figure's disengagement.

At a more complex level, there are serious clinical implications for the counselor who accepts the family's version of the problem. In doing this, the counselor surrenders his or her position as the expert and leader. If the counselor agrees with the family's assessment of "who's got the problem," the family will perceive his or her expertise and ability to understand the issues as no greater than its own. The counselor's credibility as a helper and the family's perception of his or her competence will be at stake. Some family members may perceive the counselor as unable to challenge the status quo in the family because, in fact, he or she has failed to achieve the first and defining reframe of the problem.

When the counselor agrees to see only part of the family, he or she may have surrendered his or her authority too early and may be unable to direct change and to move freely from one family member to another. Thus, by beginning counseling with only part of the family, excluded family members may see the counselor as being in a coalition with the family members who originally participated in therapy. Therefore, the family members who didn't attend the initial sessions may never come to trust the counselor. This means that the counselor will not be able to observe the system as a whole as it usually operates at home because the family members who were not involved in therapy from the beginning will not trust the counselor sufficiently to behave as they would at home. The counselor, then, will be working with the family knowing only one aspect of how the family typically interacts.

Some counselors respond to the resistance of some family members to attend counseling by agreeing to see only those who wish to come. Other family counselors have resolved the dilemma of what to do when only some family members want to go to counseling by taking a more alienated stance saying: "There are too many motivated families waiting for help; the resistant families will call back when they finally feel the need; there is no need to get involved in a power struggle." The reality is that these resistant families will most likely never come to counseling by themselves. Ironically, the families who most need counseling are those families whose patterns and habits interfere with their ability to get help for themselves.

Dealing With Resistance to Engagement
When some family members do not want to participate in treatment, the counselor needs to find out why. In most instances, when a parent ${ }^{1}$ has called the counselor asking for help, that parent is not powerful enough to bring the adolescent into counseling. If the counselor wants the family to be in counseling, he or she will have to recognize

${ }^{1}$ We remind the reader that the terms "mother," "father," and "parent" refer to other parent figures as well. 
that the youth (or a noncooperative parent figure) is the most powerful person in the family. Once the reason the family is not in treatment is understood, the counselor can draw upon the concept of tracking (as defined in Chapter 4) to find a way to reach this powerful person directly and negotiate a treatment contract to which the person will agree.

Counselors should not become discouraged at this stage. Their mission now is to identify the obstacles the family faces and help it surmount them. It is essential to keep in mind that a family seeks counseling because it is unable to overcome an obstacle without help. Failed tasks, such as not getting the family to come in for treatment, tend to be a great source of new and important information regarding the reasons why a family cannot do what is best for them. The most important question in counseling is, "What has happened that will not allow some families to do what may be best for them?"

In trying to engage the family in treatment, the counselor should apply the concept of repetitive patterns of maladaptive interaction, which give rise to and maintain symptoms, to the problem of resistance to entering treatment. The very same principles that apply to understanding family functioning and treatment also apply to understanding and treating the family's resistance to entering counseling. When the family wishes to get rid of the youth's drug abuse symptom by seeking professional help, the same interactive patterns that prevented it from getting rid of the adolescent's symptom also prevent the family from getting help. The term "resistance" is used to refer to the maladaptive interactive patterns that keep families from entering treatment. From a family-systems perspective, resistance is nothing more than the family's display of its inability to adapt effectively to the situation at hand and to collaborate with one another to seek help. Thus, the key to eliminating the resistance to counseling lies within the family's patterns of interaction; overcome the resistance in the interactional patterns and the family will come to counseling.

In working to overcome resistant patterns of family interaction, tasks play a particularly vital role because they are the only BSFT intervention used outside the therapy session. For this reason, tasks are particularly well-suited for use during the engagement period, when crucial aspects of the family's work in overcoming resistance to counseling need to take place outside the office-obviously-because the family has not yet come in.

The central task around which engagement is organized is getting the family to come to therapy together. Thus, in engagement, the counselor assigns tasks that involve doing whatever is needed to get the family into treatment. For example, a father calls a BSFT counselor and asks for help with his drug-abusing son. The counselor responds by suggesting that the father bring his entire family to a session so that he or she can involve the whole family in fixing the problem. The father responds that his son would never come to treatment and 
that he doesn't know what to do. The first task that the counselor might assign the father is to talk with his wife and involve her in the effort to bring their son into treatment.

\section{The Task of Coming to Treatment}

The simple case. The counselor gives the task of bringing the whole family into counseling to the family member who calls for help. The counselor explains why this task is a good idea and promises to support the family as it works at this task. Occasionally, this is all that is needed. Often people do not request family counseling simply because family counseling is not well known, and thus it does not occur to them to take such action.

Fear, an obstacle that might easily be overcome. Sometimes, family members are afraid of what will happen in family therapy. Some of these fears may be real; others may be simply imagined. In some instances, families just need some reassuring advice to overcome their fears. Such fears might include, "They are going to gang up on me," or "Everyone will know what a failure I am." Once these family members have been helped to overcome their fears, they will be ready to enter counseling.

Tasks to change how family members act with each other. Very often, however, simple clarification and reassurance is not sufficient to mobilize a family. It is at this point that tasks that apply joining, diagnostic, and restructuring strategies are useful in engaging the family. The counselor needs to prescribe tasks for the family members who are willing to come to therapy. These need to be tasks that attempt to change the ways in which family members interact when discussing coming to therapy. In the process of carrying out these tasks, the family's resistance will come to light. When that happens, the counselor will have the diagnostic information needed to get around the family's patterns of interaction that are maintaining the symptom of resistance. Once these patterns are changed, the family will come to therapy.

It should not be a surprise that families fail to accomplish the task of getting all of their members to counseling. In fact, the therapist's job is to belp the families accomplish tasks that they are not able to accomplish on their own. As discussed earlier, when assigning any task, the counselor must expect that the task may not be performed as requested. This is certainly the case when the family is asked to perform the task of coming together to counseling.

The application of joining, diagnosing, and restructuring techniques to the engagement of resistant families is discussed separately below. However, these techniques are used simultaneously during engagement, as they are during counseling. 


\section{Joining}

\section{Establishing a Therapeutic Alliance}

Joining the resistant family begins with the first contact with the family member who calls for help and continues throughout the entire relationship with the family.

With resistant families, the joining techniques described earlier have to be adapted to match the goal of this phase of therapy. For example, in tracking the resistant family members to engage them, it is necessary to track through the caller or initial help seeker and any other family members who may be involved in the process of bringing the family to counseling. The counselor tracks by "following" from the first family member to the next available family member to the next one and so on. This following, or tracking, is done without challenging the family patterns of interaction. Rather, tracking is accomplished by gaining the permission of one family member to reach the others.

An effective way for the counselor to establish a therapeutic alliance is to say to the resistant family members that he or she knows that they want to solve their problems and that the counselor wants the same thing. It must be recognized, however, that each family member may view the problem differently. For example, the mother may want to get her son to quit using drugs, while the son may want peace at home.

A therapeutic alliance is built around individual goals that family members can reach in therapy. Ideally, the counselor and the family members agree on a goal, and therapy is offered in the framework of achieving that goal. However, in families in which members are in conflict over their goals, it is necessary to find something for each of them to achieve in therapy. For example, the counselor can say to the mother that therapy can help her son stop using drugs, to the son that therapy can help him get his mother off his back and stop her nagging, and to the father that therapy can help stop his being called in constantly to play the "bad guy." In each case, the counselor can offer counseling as a means for each family member to achieve his or her own personal goal.

In engaging resistant families, the counselor initially works with and through only one or a few family members. Because the entire family is not initially available, the counselor will need to form a bond with the person who called for help and any other family members that make themselves available. However, the focus of this early engagement phase is strictly to work with these people to bring about the changes necessary to engage the entire family in counseling. The focus is not to talk about the problem but rather to talk about getting everyone to help solve the problem by coming to therapy. By using the contact person as a vehicle (via tracking) for joining with other members of the family, the counselor can eventually establish a therapeutic alliance with each family member and thereby elicit the cooperation of the entire family in the engagement effort. 


\section{Diagnosing the Interactions That Keep the Family From Coming Into Treatment}

In engagement, the purpose of diagnosis is to identify those particular patterns of interaction that permit the resistant behavior to continue. However, because it isn't possible to observe the entire family, the BSFT counselor works with limited information to diagnose those patterns of interaction that are supporting the resistance.

To identify the maladaptive patterns responsible for the resistance, diagnosis begins prior to therapy, when a family member first calls the counselor. Because it is not possible to encourage and observe enactments of family members interacting before they enter counseling, engagement diagnosis has been modified so that it can be used during engagement to collect the diagnostic information in other ways.

First, the counselor asks the contact person interpersonal systems questions that allow him or her to infer what the family's interactional patterns may be. For example, the counselor may ask, "How do you ask your husband to come to treatment?" "What happens when you ask your husband to come to treatment?" "When he gets angry at you for asking him to come to treatment, what do you do next?" Through these questions, the counselor tries to identify the interplay between these spouses that contributes to the resistance. For example, is it possible that the wife is asking the husband to come to treatment in an accusatory way, which causes him to get angry? An example might be, "It is your fault that your son is in trouble because you are sick. You have to go to treatment."

As was indicated earlier, counselors do not like to rely on what family members tell them because each family member is very invested in his or her own viewpoints and probably cannot provide a systemic or objective account of family functioning. However, when counselors have access to only one person, they work with the person they have, strictly for the purpose of engaging that person in treatment.

Second, counselors explore the family system for resistances to the task of coming to therapy. This is done by assigning exploratory tasks to uncover resistances that cause the family to fail at the task of coming to therapy. For example, in the case above, the counselor might suggest to the wife that she ask her husband to come for her sake and not because there is anything wrong with him. At that point, the wife may say to the counselor, "I can't really ask him for my sake because I know he's too busy to come to the family meetings." This statement suggests that the wife is not completely committed to getting the husband to come to treatment. On the one hand, she claims to want him to come to treatment, but on the other, she gives excuses for why he cannot. The purpose of exploring the resistance, beginning with the first phone call, is to identify as early as possible the obstacles that may prevent the family from coming to therapy, with the aim of intervening in a way that gets around these obstacles. 


\section{Complementarity: Understanding How the Family "Pieces" Fit Together to Create Resistance}

What makes this type of early diagnostic work possible is an understanding of the Principle of Complementarity, which was described in Chapter 2. As noted earlier, for a family to work as a unit (even maladaptively), the behaviors of each family member must "fit with" the behaviors of every other family member. Thus, for each action within the family, there is a complementary action or reaction. For example, in the case of resistance, the husband doesn't want to come to treatment (the action), and the wife excuses him for not coming to treatment (the complementary action). Similarly, a caller tells the counselor that whenever she says anything to her husband about counseling (the action), he becomes angry (the complementary reaction). The counselor needs to know exactly what the wife's contribution is to this circular transaction, that is, what her part is in maintaining this pattern of resistance.

\section{Restructuring the Resistance}

In the process of engaging resistant families, the counselor initially sees only one or a few of the family members. It is still possible, through these individuals, to bring about short-term changes in interactional patterns that will allow the family to come for therapy. A variety of change-producing interventions have already been described in Chapter 4: reframing, reversals, detriangulation, opening up closed systems, shifting alliances, and task setting. The counselor can use all of these techniques to overcome the family's resistance to counseling. In the process of engaging resistant families, task setting is particularly useful in restructuring.

The next section discusses the types of resistant families that have been identified, the process of getting the family into counseling, and the central role that tasks may play in achieving this goal. Much of counseling work with resistant families has been done with families in which the parents knew or believed the adolescent was using drugs and engaging in associated problem behaviors such as truancy, delinquency, fighting, and breaking curfew. These types of families are typically difficult to engage in therapy. However, the examples are not intended to represent all possible types of configurations of family patterns of interaction that work to resist counseling. Counselors working with other types of problems and families are encouraged to review their caseload of difficult-to-engage families and to carefully diagnose the systemic resistances to therapy. Some counselors may find that the resistant families they work with are similar to those described here, and some may find different patterns of resistance. In any case, counselors will be better equipped to work with these families if they have some understanding of the more common types of resistances in families of adolescent drug abusers. 


\section{Types of Resistant Families}

There are four general types of family patterns of interaction that emerge repeatedly in work with families of drug-abusing adolescents who resist engagement to therapy. These four patterns are discussed below in terms of how the resistant patterns of interaction are manifested, how they come to the attention of the counselor, and how the resistance can be restructured to get the family into therapy.

\section{Powerful Identified Patient}

The most frequently observed type of family resistance to entering treatment is characterized by an identified patient who has a powerful position in the family and whose parents are unable to influence him or her. This is a problem, particularly in cases that are not courtreferred and in which the adolescent identified patient is not required to engage in counseling. Very often, the parent of a powerful identified patient will admit that he or she is weak or ineffective and will say that his or her son or daughter flatly refuses to come to counseling. Counselors can assume that the identified patient resists counseling for two reasons: It threatens his or her position of power, and counseling is on the parent's agenda and compliance would strengthen the parent's power.

As a first step in joining and tracking the rules of the family, the counselor shows respect for and allies with the adolescent. The counselor contacts the drug-abusing adolescent by phone or in person (perhaps on his or her own turf, such as after school at the park). The counselor listens to the powerful adolescent's complaints about his or her parents and then offers to help the youth change the situation at home so that the parents will stop harassing him or her. This does not threaten the adolescent's power within the family and, thus, is likely to be accepted. The counselor offers respect and concern for the youth and brings an agenda of change that the adolescent will share by virtue of the alliance.

To bring these families who resist entering treatment into treatment, the counselor does not directly challenge the youth's power in the family. Instead, the counselor accepts and tracks the adolescent's power. The counselor allies himself or herself with the adolescent so that he or she may later be in a position to influence the adolescent to change his or her behavior. Initially, in forming an alliance with the powerful adolescent, the counselor reframes the need for counseling in a manner that strengthens the powerful adolescent in a positive way. This is an example of tracking-using the power of the adolescent to bring him or her into therapy. The kind of reframing that is most useful with powerful adolescents is one that transfers the symptom from the powerful adolescent/identified patient to the family. For example, the counselor may say, "I want you to come into counseling to help me change some of the things that are going on in your family." Later, once the adolescent is in counseling, the counselor will challenge the adolescent's position of power. 
It should be noted that in cases in which powerful adolescents have less powerful parents, forming the initial alliance with the parents is likely to be ineffective because the parents are not strong enough to bring their adolescent into counseling. Their failed attempts to bring the adolescent into counseling would render the parents even weaker, and the family would fail to enter counseling. Furthermore, the youth is likely to perceive the counselor as being the parents' ally, which would immediately make the adolescent distrust the weak counselor.

\section{Contact Person Protecting Structure}

The second most common type of resistance to entering treatment is characterized by a parent who protects the family's maladaptive patterns of interaction. In these families, the person (usually the mother) who contacts the counselor to request help is also the person who iswithout realizing it-maintaining the resistance in the family. The way in which the identified patient is maintained in the family is also the way in which counseling is resisted. The mother, for example, might give conflicting messages to the counselor, such as, "I want to take my family to counseling, but my son couldn't come to the session because he forgot and fell asleep, and my husband has so much work he doesn't have the time."

The mother is expressing a desire for the counselor's help while protecting and allying herself with the family's resistance to being involved in solving the problem. The mother protects this resistance by agreeing that the excuses for noninvolvement are valid. In other words, she is supporting the arguments the other family members are using to maintain the status quo. It is worthwhile to note that ordinarily this same conflicting message that occurs in the family maintains the symptomatic structure. In other words, someone complains about the problem behavior, yet supports the maintenance of the behaviors that nurture the problem. This pattern is typical of families in which the caller (e.g., the mother) and the identified patient are enmeshed.

To bring these families into treatment, the counselor must first form an alliance with the mother by acknowledging her frustration in wanting to get help and not getting any cooperation from the other family members to get it. Through this alliance, the counselor asks the mother's permission to contact the other family members "even though they are busy and the counselor recognizes how difficult it is for them to become involved." With the mother's permission, the counselor calls the other family members and separates them from the mother in regard to the issue of coming to counseling. The counselor develops his or her own relationship with other family members in discussing the importance of coming to counseling. In doing so, he or she circumvents the mother's protective behaviors. Once the family is in counseling, the mother's overprotection of the adolescent's misbehavior and of the father's uninvolvement (and the adolescent's and father's eagerness that she continue to protect them) 
will be addressed because it also may be related to the adolescent's problem behaviors.

\section{Disengaged Parent}

These family structures in which one parent protects the family's maladaptive patterns of behavior are characterized by little or no cohesiveness and lack of an alliance between the parents or parent figures as a subsystem. One of the parents, usually the father, refuses to come into therapy. This is typically a father who has remained disengaged from the problems at home. The father's disengagement not only protects him from having to address his adolescent's problems but also protects him from having to deal with the marital relationship, which is most likely the more troublesome of the two relationships he is avoiding. Typically, the mother is over-involved (enmeshed) with the identified patient and either lacks the skills to manage the youth or is supporting the identified patient in a covert fashion.

For example, if the father tries to control the adolescent's behavior, the mother complains that he is too tough or makes her afraid that he may become violent. ${ }^{2}$ The father does not challenge this portrayal of himself. He is then rendered useless and again distances himself, re-establishing the disengagement between husband and son and between husband and wife. In this family, the dimension of resonance is of foremost importance in planning how to change the family and bring it into therapy. The counselor must use tasks to bring the mother closer to the father and distance her from the son. That is, the boundary between the parents needs to be loosened to bring them closer together, and the boundary between mother and son needs to be strengthened to create distance between them.

To engage these families into treatment, the counselor must form an alliance with the person who called for help (usually the mother). The counselor then must begin to direct the mother to change her patterns of interaction with the father to improve their cooperation, at least temporarily, in bringing the family into treatment. The counselor should give the mother tasks to do with her husband that pertain only to getting the family into treatment and taking care of their son's problems. The counselor should assign tasks in a way that is least likely to spark the broader marital conflict. To set up the task, the counselor may ask the mother what she believes is the real reason her husband does not want to come to counseling. Once this reason is ascertained, the counselor coaches the mother to present the issue of coming to treatment in a way that the husband can accept. For example, if he doesn't want to come because he has given up on his son, she may be coached to suggest to him that coming to treatment will help her cope with the situation.

${ }^{2}$ Of course, some fathers are violent, and the fear may be warranted. However, even in these cases, the violent father must be brought to therapy to change his behavior and to ensure that the parents collaborate in parenting. 
Although the pattern of resistance is similar to that of the contact person protecting the structure, in this instance, the resistance emerges differently. In this case, the mother does not excuse the father's distance. To the contrary, she complains about her spouse's disinterest; this mother is usually eager to do something to involve her husband; she just needs some direction to be able to do it.

\section{Families With Secrets}

Sometimes counseling is threatening to one or more individuals in the family. Sometimes the person who resists coming to counseling is either afraid of being made a scapegoat or afraid that dangerous secrets (e.g., infidelity) will be revealed. These individuals' beliefs or frames about counseling are usually an extension of the frame within which the family is functioning. That is, it is a family of secrets.

The counselor must reframe the idea or goal of counseling in a way that eliminates its potential negative consequences and replaces them with positive aims. One example of how to do this is to meet with the person who rejects counseling the most and assure him or her that counseling does not have to go where he or she does not want it to go. The counselor needs to make it clear that he or she will make every effort to focus on the adolescent's problems instead of the issues that might concern the unwilling family member. The counselor also should assure this individual that in the counseling session, "We will deal only with those issues that you want to deal with. You'll be the boss. I am here only to help you to the extent that you say." 



\section{Chapter 6 Clinical Research Supporting Brief Stategic Family Therapy}

This chapter describes past research on the effectiveness of BSFT with drug-abusing adolescents with behavioral problems. BSFT has been found to be effective in reducing adolescents' conduct problems, drug use, and association with antisocial peers and in improving family functioning. In addition, BSFT engagement has been found to increase engagement and retention in therapy. Additional studies testing an ecological version of BSFT with this population are currently underway.

As presented in this manual, BSFT's primary emphasis is on identifying and modifying maladaptive patterns of family interaction that are linked to the adolescent's symptoms. The ecological version of BSFT, BSFT-ecological (Robbins et al. in press) applies this principle of identifying and modifying maladaptive patterns of interaction to the multiple social contexts in which the adolescent is embedded (cf. Bronfenbrenner 1979). The principal social contexts that are targeted in BSFT-ecological are family, family-peer relations, family-school relations, family-juvenile justice relations, and parent support systems. Joining, diagnosing, and restructuring, as developed in BSFT to use within the family system, are applied to these other social contexts or systems that influence the adolescent's behaviors. For instance, the BSFT counselor assesses the maladaptive, repetitive patterns of interaction that occur in each of these systems or domains. As an example, the BSFT counselor would diagnose the family-school system in the same way that he or she would diagnose the family system. In diagnosing structure, the counselor would ask, "Do parents provide effective leadership in their relationship with their child's teachers?" In diagnosing resonance, the counselor would ask, "Are parents and teachers disengaged?" In diagnosing conflict resolution, the counselor's questions would be, "What is the conflict resolution style in the parentteacher relationship? Might parents and teachers avoid conflict with each other (by remaining disengaged) or diffuse conflicts by blaming each other?" In BSFT-ecological, joining the teacher in the parentteacher relationship employs the same joining techniques developed for BSFT. Similarly, in BSFT-ecological, BSFT restructuring techniques are used to modify the nature of the relationship between a parent and his or her child's teacher. 


\section{Outpatient Brief Strategic Family Therapy Versus Outpatient Group Counseling}

A recent study (Santisteban et al. in press) examined the efficacy of BSFT in reducing an adolescent's behavioral problems, association with antisocial peers, and marijuana use, and in improving family functioning. In this study, outpatient BSFT was compared to an outpatient group counseling control treatment. Participants were 79 Hispanic families with a 12- to 18-year-old adolescent who was referred to counseling for conduct and antisocial problems by either a school counselor or a parent. Families were randomly assigned to either BSFT or group counseling. Analyses of treatment integrity revealed that interventions in both therapies adhered to treatment guidelines and that the two therapies were clearly distinguishable.

Conduct disorder and association with antisocial peers were assessed using the Revised Behavior Problem Checklist (RBPC) (Quay and Peterson 1987), which is a measure of adolescent behavior problems reported by parents. Conduct disorder was measured using 22 items, and association with antisocial peers was measured using 17 items. Each item asks the parent(s) to rate whether a specific aspect of the adolescent's behavior (e.g., fighting, spending time with "bad" friends) is no problem (0), a mild problem (1), or a severe problem (2). Ratings for all items on each scale are then added together to derive a total score.

The effects of BSFT on conduct disorder, association with antisocial peers, and marijuana use were evaluated in two ways. First, analyses of variance were conducted to examine whether BSFT reduced conduct disorder, association with antisocial peers, and marijuana use to a significantly greater extent than did group counseling. Second, exploratory analyses were conducted on clinically significant changes in conduct problems and association with antisocial peers. These exploratory analyses used the twofold clinical significance criteria recommended by Jacobson and Truax (1991). To be able to classify a change in symptoms for a given participant as clinically significant, two conditions have to occur. First, the magnitude of the change must be large enough to be reliable-that is, to rule out random fluctuation as a plausible explanation. Second, the participant must "recover" from clinical to nonclinical levels, i.e., cross the diagnostic threshold.

Conduct Disorder. Analyses of variance indicated that conduct disorder scores for adolescents in BSFT compared to those for adolescents in group counseling were significantly reduced between pre- and posttreatment. In the clinical significance analyses, a substantially larger proportion of adolescents in BSFT than in group counseling demonstrated clinically significant improvement. At intake, 70 percent of adolescents in BSFT had conduct disorder scores that were above clinical cutoffs. That is, they scored above the empirically established threshold for clinical diagnoses of conduct disorder. At the end of 
treatment, 46 percent of these adolescents showed reliable improvement, and 5 percent showed reliable deterioration. Among the 46 percent who showed reliable improvement, 59 percent recovered to nonclinical levels of conduct disorder. In contrast, at intake, 64 percent of adolescents in group counseling had conduct disorder scores above the clinical cutoff. Of these, none showed reliable improvement, and 11 percent showed reliable deterioration. Therefore, while adolescents in BSFT who entered treatment at clinical levels of conduct disorder had a 66 percent likelihood of improving, none of the adolescents in group counseling reliably improved.

Association With Antisocial Peers. Analyses of variance indicated that, for adolescents in BSFT, scores for association with antisocial peers were significantly reduced between pre- and post-treatment, compared to those for adolescents in group counseling. In the clinical significance analyses, 79 percent of adolescents in BSFT were above clinical cutoffs for association with antisocial peers at intake. Among adolescents in BSFT meeting clinical criteria for association with antisocial peers, 36 percent showed reliable improvement, and 2 percent showed reliable deterioration. Of the 36 percent of adolescents in BSFT with reliable improvement, 50 percent were classified as recovered. Among adolescents in group counseling, 64 percent were above clinical cutoffs for association with antisocial peers at intake. Among adolescents in group counseling meeting these clinical criteria at intake, 11 percent reliably improved, and none reliably deteriorated. Of the 11 percent of adolescents in group counseling evidencing reliable improvement in association with antisocial peers, 50 percent recovered to nonclinical levels. Hence, adolescents in BSFT who entered treatment at clinical levels of association with antisocial peers were 2.5 times more likely to reliable improve than were adolescents in group treatment.

Marijuana Use. Analyses of variance revealed that BSFT was associated with significantly greater reductions in self-reported marijuana use than was group counseling. To investigate whether clinically meaningful ${ }^{3}$ changes in marijuana use occurred, four use categories from the substance use literature (e.g., Brooks et al.1998) were employed. These categories are based on the number of days an individual uses marijuana in the 30 days before the intake and termination assessments:

- abstainer - 0 days

- weekly user - 1 to 8 days

- frequent user - 9 to 16 days

- daily user - 17 or more days

${ }^{3}$ Formal tests of clinically significant change in marijuana use were not possible because the measure of marijuana use does not provide both clinical and nonclinical norms. 
In BSFT, 40 percent of participants reported using marijuana at intake and/or termination. Of these, 25 percent did not show change, 60 percent showed improvement in drug use, and 15 percent showed deterioration. Of the individuals in BSFT who shifted into less severe categories, 75 percent were no longer using marijuana at termination. In group counseling, 26 percent of participants reported using marijuana at intake and/or termination. Of these, 33 percent showed no change, 17 percent showed improvement, and 50 percent deteriorated. The 17 percent of adolescents in group counseling cases that showed improvement were no longer using marijuana at termination. Hence, adolescents in BSFT were 3.5 times more likely than were adolescents in group counseling to show improvement in marijuana use.

Treatments also were compared in terms of their influence on family functioning. Family functioning was measured using the Structural Family Systems Ratings (Szapocznik et al. 1991). This measure was constructed to assess family functioning as defined in Chapter 3. Based on their scores when they entered therapy, families were separated by a median split into those who had good and those who had poor family functioning. Within each group (i.e., those with good and those with poor family functioning), a statistical test that compares group means (analysis of variance) tested changes in family functioning from before to after the intervention.

Among families who were admitted with poor family functioning, the results showed that those assigned to BSFT had a significant improvement in family functioning, while those families assigned to group counseling did not improve significantly.

Among families who were admitted with good family functioning, the results showed that those assigned to BSFT retained their good levels of family functioning, while families assigned to group counseling showed significant deterioration. These findings suggest that not all families of drug-abusing youths begin counseling with poor family functioning, but if the family is not given adequate help to cope with the youth's problems, the family's functioning may deteriorate.

\section{One Person Brief Strategic Family Therapy}

With the advent of the adolescent drug epidemic of the 1970s, the vast majority of counselors who worked with drug-using youths reported that, although they preferred to use family therapy, they were not able to bring whole families into treatment (Coleman and Davis 1978). In response, a procedure was developed that would achieve the goals of BSFT (to change maladaptive family interactions and symptomatic adolescent behavior) without requiring the whole family to attend treatment sessions. The procedure is an adaptation of BSFT called "One Person" BSFT (Szapocznik et al. 1985; Szapocznik and Kurtines 1989; Szapocznik et al. 1989a). One Person BSFT capitalizes on the systemic concept of complementarity, which suggests that when one family member changes, the rest of the system 
responds by either restoring the family process to its old ways or adapting to the new changes (Minuchin and Fishman 1981). The goal

of One Person BSFT is to change the drug-abusing adolescent's participation in maladaptive family interactions that include him or her. Occasionally, these changes create a family crisis as the family attempts to return to its old ways. The counselor uses the opportunity created by these crises to engage reluctant family members.

A clinical trial was conducted to compare the efficacy of One Person BSFT to Conjoint (full family) BSFT (Szapocznik et al. 1983, 1986). Hispanic families with a drug-abusing 12- to 17-year-old adolescent were randomly assigned to the One Person or Conjoint BSFT modalities. Both therapies were designed to use exactly the same BSFT theory so that only one variable (one person vs. conjoint meetings) would differ between the treatments. Analyses of treatment integrity revealed that interventions in both therapies adhered to guidelines and that the two therapies were clearly distinguishable. The results showed that One Person was as efficacious as Conjoint BSFT in significantly reducing adolescent drug use and behavior problems as well as in improving family functioning at the end of therapy. These results were maintained at the 6-month followup (Szapocznik et al. 1983, 1986).

One Person BSFT is not discussed in this manual because it is considered a very advanced clinical technique. More information on One Person BSFT is available in Szapocznik and Kurtines (1989).

\section{Brief Strategic Family Therapy Engagement}

As discussed in Chapter 5, in response to the problem of engaging resistant families, a set of engagement procedures based on BSFT principles was developed (Szapocznik and Kurtines 1989; Szapocznik et al. 1989b). These procedures are based on the premise that resistance to entering treatment can be understood in family interactional terms.

One Person BSFT techniques are useful in this initial phase. That's because the person who contacts the counselor to request help may become the one person through whom work is initially done to restructure the maladaptive family interactions that are maintaining the symptom of resistance. The success of the engagement process is measured by the family's and the symptomatic youth's attendance in family therapy. In part, success in engagement permits the counselor to redefine the problem as a family problem in which all family members have something to gain. Once the family is engaged in treatment, the focus of the intervention is shifted from engagement to removing the adolescent's presenting symptoms.

The efficacy of BSFT engagement has been tested in three studies with Hispanic youths (Szapocznik et al. 1988; Santisteban et al. 1996; Coatsworth et al. 2001). The first study (Szapocznik et al. 1988) included mostly Cuban families with adolescents who had behavior problems 
and who were suspected of or observed using drugs by their parents or school counselors. Of those engaged, 93 percent actually reported drug use. Families were randomly assigned to one of two therapies: BSFT engagement or engagement as usual (the control therapy). The engagement-as-usual therapy consisted of the typical engagement methods used by community treatment agencies, which were identified prior to the study using a community survey of outpatient agencies serving drug-abusing adolescents. All families who were successfully engaged received BSFT. In the experimental therapy, families were engaged and retained using BSFT engagement techniques. Successful engagement was defined as the conjoint family (minimally the identified patient and his or her parents and siblings living in the same household) attending the first BSFT session, which was usually to assess the drug-using adolescent and his or her family. Treatment integrity analyses revealed that interventions in both engagement therapies adhered to prescribed guidelines using six levels of engagement effort that were operationally defined and that the therapies were clearly distinguishable by level of engagement effort applied.

The six levels of engagement effort, as enumerated in Szapocznik et al. (1988, p. 554), are:

- Level 0 - expressing polite concern, scheduling an intake appointment, establishing that cases met criteria for inclusion in the study, and making clear who must attend the intake assessment;

- Level 1 - attempting minimal joining, encouraging the caller to involve the family, asking about the depth and breadth of adolescent problems, and asking about family members;

- Level 2 - attempting more thorough joining; asking about family interactions; seeking information about the problems, values, and interests of family members; supporting and establishing an alliance with the caller; beginning to establish leadership; and asking whether all family members would be willing to attend the intake appointment;

- Level 3 - restructuring for engagement through the caller, advising the caller about negotiating and reframing, and following up with family members (either over the phone or personally with the caller at the therapist's office) to be sure that intake appointments would be kept;

- Level 4 - conducting lower level ecological engagement interventions, joining family members or conducting intrapersonal restructuring (with family members other than the original caller) over the phone or in the therapist's office, and contacting significant others (by phone) to gather more information; and 
- Level 5 - conducting higher level ecological interventions, making out-of-office visits to family members or significant others, and using significant others to help conduct restructuring.

Level $0-1$ behaviors were permitted for both the BSFT engagement and engagement-as-usual conditions. Level 2-5 behaviors were permitted only for the BSFT engagement condition. Efficacy was measured in rates of both family treatment entry as well as retention to treatment completion.

The efficacy of the two methods of engagement was measured by the percentage of families who entered treatment and the percentage of families who completed the treatment. The results revealed that 42 percent of the families in the engagement-as-usual therapy and 93 percent of the families in the BSFT engagement therapy were successfully engaged. In addition, 25 percent of engaged cases in the engagement-as-usual treatment and 77 percent of engaged cases in the BSFT engagement treatment successfully completed treatment. These differences in engagement and retention between the two methods of engagement were both statistically significant. Improvements in adolescent symptoms occurred but were not significantly different between the two methods of engagement. Thus, the critical distinction between the treatments was in their different rates of engagement and retention. Therefore, BSFT engagement had a positive impact on more families than did engagement as usual.

In addition to replicating the previous engagement study, the second study (Santisteban et al. 1996) also explored factors that might moderate the efficacy of the engagement interventions. In contrast to the previous engagement study, Santisteban et al. (1996) more stringently defined the success of engagement as a minimum of two office visits: the intake session and the first therapy session. The researchers randomly assigned 193 Hispanic families to one experimental and two control treatments. The experimental therapy was BSFT plus BSFT engagement. The first control therapy was BSFT plus engagement as usual, and the second was group counseling plus engagement as usual. In both control treatments, engagement as usual involved no specialized engagement strategies.

Results showed that 81 percent of families were successfully engaged in the BSFT plus BSFT engagement experimental treatment. In contrast, 60 percent of the families in the two control therapies were successfully engaged. These differences in engagement were statistically significant. However, the efficacy of the experimental therapy procedures was moderated by the cultural/ethnic identity of the Hispanic families in the study. Among families assigned to BSFT engagement, 93 percent of the non-Cuban Hispanics (composed primarily of Nicaraguan, Colombian, Puerto Rican, Peruvian, and Mexican families) and 64 percent of the Cuban Hispanics were engaged. These findings 
have led to further study of the mechanism by which culture/ethnicity and other contextual factors may influence clinical processes related to engagement (Santisteban et al. 1996; Santisteban et al. in press). The results of the Szapocznik et al. (1988) and Santisteban et al. (1996) studies strongly support the efficacy of BSFT engagement. Further, the second study with its focus on cultural/ethnic identity supports the widely held belief that therapeutic interactions must be responsive to contextual changes in the treatment population (Sue et al. 1994; Szapocznik and Kurtines 1993).

A third study (Coatsworth et al. 2001) compared BSFT to a community control intervention in terms of its ability to engage and retain adolescents and their families in treatment. An important aspect of this study was that an outside treatment agency administered the control intervention. Because of that, the control intervention (e.g., usual engagement strategies) was less subject to the influence of the investigators. Findings in this study, as in previous studies, showed that BSFT was significantly more successful, at 81 percent, in engaging adolescents and their families in treatment than was the community control treatment, at 61 percent. Likewise, among those engaged in treatment, a higher percentage of adolescents and their families in BSFT, at 71 percent, were retained in treatment compared to those in the community control intervention, at 42 percent. In BSFT, 58 percent of adolescents and their families completed treatment compared to 25 percent of those in the community control intervention. Families in BSFT were 2.3 times more likely both to be engaged and retained in treatment than were families randomized to the community control treatment.

An additional finding of the Coatsworth et al. (2001) study warrants special mention. In BSFT, families of adolescents with more severe conduct problem symptoms were more likely to remain in treatment than were families of adolescents whose conduct problem symptoms were less severe. The opposite pattern was evident in the community control intervention, with families that were retained in treatment showing lower intake levels of conduct problems than did families who dropped out. These findings are particularly important because they suggest that adolescents who are most in need of services are more likely to stay in BSFT than in traditional community treatments. 


\section{References}

Alexander, J.F.; Holtzworth-Munroe, A.; and Jameson, P.B. The process and outcome of marital and family therapy: Research review and evaluation. In A.E. Bergin, and S.L. Garfield (eds.), Handbook of Psychotherapy and Behavior Change. New York: John Wiley and Sons, pp. 595-630, 1994.

Bergin, A.E., and Garfield, S.L. (eds.), Handbook of Psychotherapy and Behavior Change. New York: John Wiley and Sons. 1994.

Bronfenbrenner, U. Toward an experimental ecology of human development. American Psychologist 32:513-531, 1977.

Bronfenbrenner, U. The Ecology of Human Development: Experiments by Nature and Design. Cambridge, MA: Harvard University Press. 1979.

Bronfenbrenner, U. Ecology of the family as a context for human development. Developmental Psychology 22:723-42, 1986.

Bronfenbrenner, U. Interacting systems in human development: Research paradigms: Present and future. In N. Bolger; A. Caspi; G. Downey; and M. Moorehouse (eds.), Persons in Context: Developmental Processes. New York: Cambridge University Press, pp. 25-49, 1988.

Brook, J.S.; Brook, D.W.; de la Rosa, M.; Duque, L.F.; Rodriguez, E.; Montoya, I.D.; and Whiteman, M. Pathways to marijuana use among adolescents: Cultural/ecological, family, peer, and personality influences. Journal of the American Academy of Child and Adolescent Psychiatry 37:759-766, 1998.

Brook, J.S.; Kessler, R.C.; and Cohen, P. The onset of marijuana use from preadolescence and early adolescence to young adulthood. Development and Psychopathology 11:901-914, 1999.

Bush, P.J.; Weinfurt, K.P.; and Iannotti, R.J. Families versus peers: Developmental influences on drug use from grade 4-5 to grade 7-8. Journal of Applied Developmental Psychology 15:437-456, 1994.

Coleman, S.B., and Davis, D.E. Family therapy and drug abuse: A national survey. Family Process 17:21-29, 1978.

Coatsworth, J.D.; Santisteban, D.A.; McBride, C.K; and Szapocznik, J. Brief strategic family therapy versus community control: Engagement, retention, and an exploration of the moderating role of adolescent symptom severity. Family Process 40:313-332, 2001. 
Diamond, G.M.; Liddle, H.A.; Hogue, A.; and Dakof, G.A. Alliancebuilding interventions with adolescents in family therapy: A process study. Psychotherapy 36:355-369, 1999.

Diamond, G.S., and Liddle, H.A. Resolving a therapeutic impasse between parents and adolescents in multidimensional family therapy. Journal of Consulting and Clinical Psychology 64:481488, 1996.

Haley, J. Problem-Solving Therapy: New Strategies for Effective Family Therapy. San Francisco: Jossey-Bass. 1976.

Hayes, S.C.; Strosahl, K.D.; and Wilson, K.G. Acceptance and Commitment Therapy: An Experiential Approach to Behavior Change. New York: Guilford Press, 1999.

Henricson, C., and Roker, D. Support for the parents of adolescents: A review. Journal of Adolescence 23:763-783, 2000.

Jacobson, N.S., and Truax, T. Clinical significance: A statistical approach to defining meaningful change in psychotherapy research. Journal of Consulting and Clinical Psychology 59:12-19, 1991.

Jessor, R., and Jessor, S.L. Problem Behavior and Psychosocial Development: A Longitudinal Study of Youth. New York: Academic Press. 1977.

Lantz, J., and Gregoire, T. Existential psychotherapy with Vietnam veteran couples: A twenty-five year report. Contemporary Family Therapy 22:19-37, 2000.

Liddle, H.A. The anatomy of emotions in family therapy with adolescents. Journal of Adolescent Research 9:120-157, 1994.

Liddle, H.A. Conceptual and clinical dimensions of a multidimensional, multisystems engagement strategy in family-based adolescent treatment. Psychotherapy 32:39-58, 1995.

Liddle, H.A. Multidimensional Family Therapy: A Treatment Manual. Cannabis Youth Treatment Manual Series Vol. 5. DHHS Pub. No. BKD388. Rockville, MD: Center for Substance Abuse Treatment. 2002.

Liddle, H.A., and Dakof, G.A. Family-based treatment for adolescent drug use: State of the science. In E. Rahdert, ed., Adolescent Drug Abuse: Clinical Assessment and Therapeutic Interventions. NIDA Research Monograph Series No. 156. NIH Publication No. 95-3098. Rockville, MD: National Institute on Drug Abuse, pp. 218-254, 1995.

Mason, C.A.; Cauce, A.M.; Gonzales, N.; Hiraga, Y.; and Grove, K. An ecological model of externalizing behaviors in African-American adolescents: No family is an island. Journal of Research on Adolescence 4:639-655, 1994.

Minuchin, S. Families and Family Therapy. Cambridge, MA: Harvard University Press. 1974. 
Minuchin, S., and Fishman, H.C. Family Therapy Techniques. Cambridge, MA: Harvard University Press. 1981.

Minuchin, S.; Montalvo, B.; Guerney, B.G.; Rosman, B.L.; and Schumer, F. Families of the Slums. New York: Basic Books. 1967.

Mitrani, V.B.; Szapocznik, J.; and Robinson Batista, C. Structural ecosystems therapy with HIV+ African-American women. In W. Pequegnat, and J. Szapocznik (eds.), Working With Families in the Era of HIV/AIDS. Thousand Oaks, CA: Sage, pp. 243-279, 2000.

Newcomb, M.D., and Bentler, P.M. Substance use and abuse among children and teenagers. American Psychologist 44:242-248, 1989.

Ozechowski, T.J., and Liddle, H.A. Family-based therapy for adolescent drug abuse: Knowns and unknowns. Clinical Child and Family Psychology Review 3(4):269-298, 2000.

Patterson, G.R. Coercive Family Process. Eugene, OR: Castalia. 1982.

Patterson, G.R., and Dishion, T.J. Contributions of families and peers to delinquency. Criminology 23:63-79, 1985.

Patterson, G.R.; Reid, J.B.; and Dishion, T.J. Antisocial Boys. Eugene, OR: Castalia. 1992.

Perrino, T.; Gonzalez-Soldevilla, A.; Pantin, H.; and Szapocznik, J. The role of families in adolescent HIV prevention: A review. Clinical Child and Family Psychology Review 3(2):81-96, 2000.

Quay, H.C., and Peterson, D.R. Manual for the Revised Behavior Problem Checklist. Unpublished manuscript, University of Miami, Coral Gables, FL, 1987.

Rector, N.A.; Zuroff, D.A.; and Segal, Z.V. Cognitive change and the therapeutic alliance: The role of technical and nontechnical factors in cognitive therapy. Psychotherapy 36:320-328, 1999.

Robbins, M.S.; Alexander, J.F.; and Turner, C.W. Disrupting defensive family interactions in family therapy with delinquent youth. Journal of Family Psychology 14:688-701, 2000.

Robbins, M.S.; Schwartz, S.J.; and Szapocznik, J. Structural ecosystems therapy with adolescents exhibiting disruptive behavior disorders. In J.R. Ancis, ed., Culturally Based Interventions: Alternative Approaches to Working With Diverse Populations and CultureBound Syndromes, New York: Brunner-Routledge, in press.

Robbins, M.S.; Szapocznik, J.; Alexander, J.F.; and Miller, J. Family systems therapy with children and adolescents. In M. Hersen, and A.S. Bellack (series eds.), and T.H. Ollendick, vol. ed. Comprehensive Clinical Psychology: Vol. 5, Children and Adolescents: Clinical Formulation and Treatment. Oxford, United Kingdom: Elsevier Science Limited, Inc., pp. 149-180, 1998. 
Santisteban, D.A.; Coatsworth, J.D.; Briones, E.; and Szapocznik, J. Acculturation and Parenting, manuscript submitted for publication. University of Miami. 2003.

Santisteban, D.A.; Coatsworth, J.D.; Perez-Vidal, A.; Kurtines, W.M.; Schwartz, S.J.; LaPerriere, A.; and Szapocznik, J. The efficacy of Brief Strategic Family Therapy in modifying Hispanic adolescent behavior problems and substance use. Journal of Family Psychology, in press.

Santisteban, D.A.; Muir-Malcolm, J.A.; Mitrani, V.B.; and Szapocznik, J. Integrating the study of ethnic culture and family psychology intervention science. In H. Liddle, D. Santisteban, R. Levant, and J. Bray (eds.), Family Psychology: Science Based Interventions. Washington, DC: American Psychological Association Press, pp. 331-352, 2002.

Santisteban, D.A.; Szapocznik, J.; and Kurtines, W.M. Behavior problems among Hispanic youths: The family as moderator of adjustment. In J. Szapocznik, ed., A Hispanic/Latino Family Approach to Substance Abuse Prevention. OSAP Prevention Monograph No. 8. DHHS Pub. No. 91-1725. Rockville, MD: Center for Substance Abuse Prevention, pp. 19-40, 1994.

Santisteban, D.A.; Szapocznik, J.; Perez-Vidal, A.; Kurtines, W.M.; Murray, E.J.; and Laperriere, A. Efficacy of intervention for engaging youth and families into treatment and some variables that may contribute to differential effectiveness. Journal of Family Psychology 10:35-44, 1996.

Scheier, L.M., and Newcomb, M.D. Differentiation of early adolescent predictors of drug use versus abuse: A developmental risk-factor model. Journal of Substance Abuse 3:277-299, 1991.

Silverberg, S.B. Parents' well-being at their children's transition to adolescence. In C.D. Ryff, and M.M. Seltzer (eds.), The Parental Experience at Midlife. Chicago: University of Chicago Press, pp. 216-254, 1996.

Steinberg, L. Adolescent transitions and alcohol and other drug use prevention. In E.N. Goplerud, ed., Preventing Adolescent Drug Use: From Theory to Practice. OSAP Prevention Monograph No. 8. DHHS Pub. No. 91-1725. Rockville, MD: U.S. Department of Health and Human Services, Office for Substance Abuse Prevention, pp. 13-51, 1991.

Steinberg, L. Adolescence, 5th ed. New York: McGraw-Hill. 1998.

Steinberg, L.; Fletcher, A.; and Darling, N. Parental monitoring and peer influences on adolescent substance use. Pediatrics 93:10601064, 1994.

Stiles, W.B.; Agnew-Davies, R.; Hardy, G.E.; Barkham, M.E.; and Shapiro, D.A. Relations of alliance with psychotherapy outcome: Findings in the Second Sheffield Psychotherapy Project. Journal of Consulting and Clinical Psychology 66:791-802, 1998. 
Sue, S. In search of cultural competence in psychotherapy and counseling. American Psychologist 54:440-448, 1998.

Sue, S.; Zane, N.; and Young, K. Research on psychotherapy with culturally diverse populations. In A.E. Bergin, and S.L. Garfield (eds.), Handbook of Psychotherapy and Behavior Change. New York: John Wiley and Sons, Inc., pp. 783-817, 1994.

Szapocznik, J., and Coatsworth, J.D. An ecodevelopmental framework for organizing the influences on drug abuse: A developmental model of risk and protection. In M. Glantz, and C.R. Hartel (eds.), Drug abuse: Origins and Interventions. Washington, DC: American Psychological Association, pp. 331366, 1999.

Szapocznik, J., and Kurtines, W. Acculturation, biculturalism, and adjustment among Cuban Americans. In A.M. Padilla (ed.), Psychological Dimensions on the Acculturation Process: Theory, Models, and Some New Findings. Boulder, CO: Westview, pp. 139-159, 1980.

Szapocznik, J., and Kurtines, W.M. Breakthroughs in Family Therapy With Drug-Abusing and Problem Youth. New York: Springer. 1989.

Szapocznik, J., and Kurtines, W.M. Family psychology and cultural diversity: Opportunities for theory, research, and application. American Psychologist 48:400-407, 1993.

Szapocznik, J.; Kurtines, W.M.; Foote, F.; Perez-Vidal, A.; and Hervis, O.E. Conjoint versus one person family therapy: Some evidence for effectiveness of conducting family therapy through one person. Journal of Consulting and Clinical Psychology 51:889-899, 1983.

Szapocznik, J.; Kurtines, W.M.; Foote, F.; Perez-Vidal, A.; and Hervis, O.E. Conjoint versus one person family therapy: Further evidence for the effectiveness of conducting family therapy through one person. Journal of Consulting and Clinical Psychology 54:395397, 1986.

Szapocznik, J.; Kurtines, W.M.; Perez-Vidal, A.; Hervis, O.E.; and Foote, F. One person family therapy. In R.A. Wells, and V.J. Giannetti (eds.), Handbook of the Brief Psychotherapies. New York: Plenum, pp. 493-510, 1989a.

Szapocznik, J.; Foote, F.; Perez-Vidal, A.; Hervis, O.E.; and Kurtines, W.M. One Person Family Therapy. Miami: Miami World Health Organization Collaborating Center for Research and Training in Mental Health, Alcohol, and Drug Dependence, Department of Psychiatry, University of Miami School of Medicine (softcover). 1985. 
Szapocznik, J.; Perez-Vidal, A.; Brickman, A.; Foote, F.H.; Santisteban, D.; Hervis, O.E.; and Kurtines, W.M. Engaging adolescent drug abusers and their families into treatment: A Strategic Structural Systems approach. Journal of Consulting and Clinical Psychology 56:552-557, 1988.

Szapocznik, J.; Perez-Vidal A.; Hervis, O.E.; Brickman, A.L.; and Kurtines, W.M. Innovations in family therapy: Strategies for overcoming resistance to treatment. In R.A. Wells, and V.J. Giannetti (eds.), Handbook of the Brief Psychotherapies. New York: Plenum, pp. 93-114, 1989b.

Szapocznik, J.; Rio, A.T.; Hervis, O.E.; Mitrani, V.B.; Kurtines, W.M.; and Faraci, A.M. Assessing change in family functioning as a result of treatment: The Structural Family Systems Rating Scale (SFSR). Journal of Marital and Family Therapy 17:295-310, 1991.

Szapocznik, J.; Scopetta, M.A.; and King, O.E. Theory and practice in matching treatment to the special characteristics and problems of Cuban immigrants. Journal of Community Psychology 6:112-122, 1978.

Vega, W.A., and Gil, A.G. A model for explaining drug use behavior among Hispanic adolescents. Drugs and Society 14:57-74, 1999.

White, L. Co-residence and leaving home: Young adults and their parents. Annual Review of Sociology 20:81-102, 1994.

Woehrer, C.E. Ethnic families in the Circumplex Model: Integrating nuclear with extended family systems. In D.H. Olson, C.S. Russell, and D.H. Sprenkle (eds.), Circumplex Model: Systemic Assessment and Treatment of Families. New York: Haworth Press, pp. 199-328, 1989. 


\section{Appendices}





\section{Appendix A Training Counselors in Brief Strategic Family Therapy}

One of BSFT's strengths is its considerable flexibility, which makes it extremely adaptable to a broad range of family and youth situations and problems. The disadvantage of BSFT is that it is not a simple-tofollow recipe (a pinch of empathy and an ounce of joining). Rather, BSFT is an advanced clinical model that requires the counselors who use it to have considerable skill.

\section{Selecting Counselors}

Level One: Training in Basic Clinical Skills Common to Many Behavioral Interventions
Counselors need three levels of training and experience to conduct BSFT counseling. If a counselor does not have basic counseling skills, he or she would have to learn them. If a counselor does not have systemic skills, he or she would have to learn them. However, if the counselor already has basic skills and systemic skills, he or she only would have to learn skills specific to BSFT. The nature of the training and skills of the counselor should be an important consideration in selecting counselors for training in BSFT. Each of the following levels of training are discussed in more detail below:

- Basic clinical skills common to many behavioral interventions

- Training in basic family systems theory, as used in many family therapy approaches

- Training specific to BSFT

Level one training is the kind of training that teaches counselors basic clinical skills common to many kinds of behavioral interventions, such as:

- Interviewing skills

- Active listening - reflecting back or repeating to the client the content and feelings the client has expressed

- Timing - knowing the right moment to say or do what the client needs 
Level Two: Training in Basic Family Systems Theory

\section{Level Three:}

Brief Strategic Family Therapy Specific Training
- Empathy - understanding the client's experience at a cognitive and affective level and being able to express it

- Treating all clients with respect

- Providing counseling for the benefit of the client and not for the benefit of the counselor; placing the client's needs above the counselor's needs

- Understanding oneself - feelings, reactions, what pushes one's buttons

- Providing validation and support to clients

Level two training is the kind of training that is often provided in clinically oriented, master's level programs in social work, marriage and family therapy, and, occasionally, in counseling psychology. In this kind of training, counselors learn how to understand families as systems rather than as a conglomerate of individuals. Systemic work, as defined in Chapter 2, is based on the notion that family members are interdependent and that the family is more than the sum of its parts. That is, family members behave very differently when they are together than when they are apart. Consequently, the counselor may not always be able to predict how a family member behaves in the family as compared to the behavior of the family member outside the family. Similarly, family members' perceptions or reports of family interactions may be severely flawed. Counselors are taught to think and act in systems terms. That means that counselors are taught to consider how social context affects individual behavior. Counselors also have been taught the basics of entering a system, such as identifying and respecting the system's power structure.

Counselors who have basic clinical skills and family systems training can be trained in BSFT concepts and techniques. However, counselors who lack basic skills training are required to take extensive prerequisite preparatory training. Counselors who lack family systems training must be trained in family systems (see Chapter 2) before they can be trained in BSFT concepts and techniques. It is suggested that counselors and their administrators should not underestimate the importance of obtaining the more basic counseling skills or the intensity of training required to obtain these more basic skills.

\section{Required Brief Strategic Family Therapy Training: Four Phases}

The required BSFT training has four phases.

- Phase 1 - counselors learn the methods of BSFT

- Phase 2 - counselors review videotapes to learn how to identify family process and family interactions 
- Phase 3 - counselors review videotapes to learn how family counseling interventions are conducted

- Phase 4 - A BSFT supervisor supervises the BSFT counselors' therapy sessions or reviews videotapes of the therapy

In the first phase of training, the counselors must learn the methods of BSFT presented in this manual. As part of teaching these methods, considerable role playing is conducted to illustrate various aspects of the BSFT model.

In the second phase of training, counselors review a series of videotapes of families that were treated at the University of Miami Center for Family Studies, where BSFT was developed. This set of videotapes shows families by themselves (without a therapist present) responding to three standard stimuli. The three standard stimuli are tasks the family has been asked to do: (1) plan a menu together with which everyone agrees; (2) say what each likes and doesn't like about each other; and (3) talk about a recent argument, including what it was about, who was involved, and what happened. These videotapes are used to teach the counselors how to identify family process and family interactions at the most minute level, as discussed in Chapter 3. In other words, counselors are taught to identify who the family's leader is, how the family handles conflicts, who is allied with whom, and who the family's identified patient is. The counselors also learn how to tell if the family views itself as having problems other than the problems of the identified patient and which family members are enmeshed, which are disengaged, and so on. As part of this phase, counselors will be trained to identify how the behaviors of one family member are linked to those of another. For example, there may be two family members who always agree or always disagree with each other; this denotes an enmeshed alliance between these family members.

In the third phase of training, the counselors review videotapes of therapy sessions BSFT counselors conducted at the Center for Family Studies with families of drug-abusing adolescents. These sessions will be used to illustrate how counselors respond to various family processes, for example, how to join with a family, reframe negativity, shift boundaries, and other techniques. Trainees will observe what trained BSFT counselors do in the context of specific family interactions (e.g., blaming the identified patient). For example, it is important to note whether the counselor reframes or diverts the conversation, permits negativity to go unchecked for a long time, centralizes the conversation around himself or herself, or decentralizes the conversation so that most of the conversation is among family members. It is also important to note how the counselor brings about these various therapeutic maneuvers, both those that are effective and those that are not.

In the fourth and final phase of training, a BSFT trainer supervises a counselor's work in BSFT sessions as it takes place whenever possible, 
or if live supervision is not possible, reviews the counselor trainee's videotapes of the family sessions. BSFT trainees are taught to be comfortable with someone videotaping their work, to discuss videotaping with families, and to obtain a signed videotape permission form from the families. In addition, the BSFT counselor trainee also will be taught to explain the nature of the training activity and the supervisory relationship to the families so that they are fully informed that they are participating in the training of the counselor.

While counselors often fear that the families they work with might object to being videotaped, 30 years of experience has shown that families are willing and comfortable when the counselors themselves are comfortable with having their work videotaped. Thus, the highest priority is to help counselors become comfortable with having their work videotaped. Drug-abusing adolescents and their families usually do not have a problem with being videotaped. However, in our experience, when a parent is involved in high-level criminal activity, that parent is likely to refuse videotaping.

While some counseling modalities may be primarily concerned with the internal experience of clients and counselors, BSFT is primarily concerned with interactions, or linked behaviors. Both the interactions between family members and the interactions between the counselor and family members help the BSFT counselor understand the problematic interactions in a family. To diagnose a family's problems, the BSFT counselor observes the way families interact in the present (i.e., process), rather than attending to the details of the aspects of family life that they discuss (i.e., content). Similarly, to understand how a counselor interacts with a family, BSFT assumes that it is extremely difficult to adequately describe interactions between the counselor and the family, and so requires the use of live supervision or supervision using videotaped therapy sessions.

The authors' preference is to collaborate with counselor trainees in their therapy as a way of teaching BSFT. Therefore, BSFT trainers will be at the other end of a one-way mirror or a camera to help counselor trainees with their first BSFT cases. This is called "live supervision." In most training settings, the most likely approach to live supervision will be through a camera. The wide-angle lens camera is set in the therapy room, and it is connected by cable to a monitor in another room. In this fashion, the trainer can watch the session live on the monitor as it is being conducted in the therapy room.

In live supervision, the trainer is a collaborator who, along with the counselor, takes responsibility for the success of the session. From time to time, the trainer will knock on the door to have the counselor come out to discuss the direction of the session and to make recommendations. If phones connect the therapy and viewing rooms, the trainer is likely to call the counselor trainee with suggestions. Sometimes, in the case of very difficult families, the trainer may actually join the counselor trainee in the counseling session to co-conduct the session. 


\section{Required Supervision}

BSFT was developed and evaluated for efficacy with counselors who had a lot of supervision. Therefore, to be implemented faithfully, BSFT must be implemented with plenty of supervision. There are several reasons why this is important. First, supervision is a support system for the counselor. Such support systems can help the trainee remain faithful to the model. Second, a counselor who works with families may encounter certain dangers that supervision and/or a supervisory support system can prevent. The most significant danger is that the counselor will be incorporated into the family system in a way that prevents the counselor from helping the family change. Because of this, beginning and intermediate BSFT counselors must be supervised abundantly during their therapy sessions. Supervisors are responsible for ensuring that counselor skills continuously improve and that counselors are faithful to the BSFT model.

There are four levels of counseling expertise:

- Trainee

- Counselor

- Senior counselor

- Master counselor

The BSFT trainee is in the early stages of learning. The BSFT counselor already knows the model but requires additional practice. The senior BSFT counselor is able to teach the model and may still require occasional supervision. The master BSFT counselor has treated several hundred families under supervision and is widely recognized as an excellent teacher. His or her videotaped sessions are used as examples to train other counselors. The master BSFT counselor conducts live demonstrations of BSFT in front of large audiences. The master counselor's skills must be of such high quality that he or she can conduct a counseling session with an unknown family, at an unknown venue, in front of a large audience, usually of more than 100 counselors, and do a great job.

How rapidly counselors advance in their careers depends on the amount of clinical work they do, the amount of supervision available, and how diligently they study their own videotapes, participate in self-study and supervisory groups, and seek additional training. Of course, how rapidly trainees move from stage to stage also depends on their beginning level of clinical and family systems expertise and on the amount of prior family counseling training and experience they have. 



\section{Appendix B Case Examples}

This appendix presents two examples of families who have undergone BSFT. These families come to therapy with different problems and illustrate different types of problematic family interactions. Dissimilar examples are provided to illustrate how BSFT can be used to work with different types of family problems.

These case examples reflect, as much as possible, the realities of the cases from which they were drawn. However, all identifying information has been changed to protect the identities of the family members.

\section{Case Example I: The Guerrero Family}

Clinical Presentation

\section{Establishing the Therapeutic System}

The Guerrero family consists of a mother, a father, and 11- and 14year-old sons. They were referred to the clinic by the 14-year-old's school counselor after he was caught smoking marijuana in the school bathroom. The counselor visited the home and found the youngest son and the mother eating dinner. The identified patient and the father were not there. The mother immediately began to list excuses why her oldest son was not home when he should have been. She had trouble accepting what the school counselor had done and insisted that the teacher who had reported him "has it out for my son."

Toward the end of the counselor's first visit, the father came home. He ignored his wife and younger son and went directly to the kitchen. Upon finding no food ready for him, he shouted over his shoulder at his wife, asking her why she had not made him dinner. When the father was asked to join the session, he declined, saying that his wife was in charge of discipline and that she was not doing a good job at it. The 14-year-old did not come home during the counselor's visit.

When the counselor first arrived at the Guerrero home, he began to join with the mother. He sat at the dinner table with the mother and the younger son and validated the mother as she complained about the father's disengagement and the oldest son's out-of-control behavior. The younger son chimed in periodically about his older brother's sour attitude, and the counselor empathized with his grievances. 


\section{Diagnosis}

Although the counselor's initial attempts to join with the father were unsuccessful, the counselor later adopted a more focused approach. When he spoke to the father, the counselor emphasized that his participation was needed to keep his son from getting into more serious trouble. The counselor also assured the father that participating in therapy could help reduce his wife's nagging about his disengagement from the family.

Joining with the drug-abusing son was somewhat more difficult. He resisted the counselor's first few attempts to join with him over the phone and was absent from the home during the counselor's first few visits. Finally, the counselor approached the adolescent at the park after he and his father had had a major fight. The counselor assured the youth that being in BSFT could help ensure that that type of fight would not happen again.

When the counselor met with the whole family, the mother began to tell him about her son's problems. The counselor asked the mother to tell her son about her concerns. As the counselor encouraged the family members to speak with each other, he also observed the patterns of interaction along the following BSFT diagnostic dimensions.

\section{Organization}

A strong alliance exists between the mother and her 14-year-old (problem) son; the father is uninvolved. The children communicate with the father mostly through the mother. The mother and the father do not share much time as a couple. The mother is responsible for child-rearing nearly all the time. The mother and father ally occasionally, but only regarding unimportant issues such as what to eat for dinner.

\section{Resonance}

The mother indicates what her 14-year-old son prefers to eat, and the mother and her 14-year-old son laugh together, both signs of enmeshment. The father is frequently "too busy" to participate in family activities, a sign of disengagement. Complaints of family members about other family members during the interview are highly specific, a sign of adaptive functioning along this dimension.

\section{Developmental Stage}

The children are not allowed to play outdoors at night. The mother uses her 14-year-old son as her confidante, complaining to him that his father comes home late.

\section{Life Context}

The father has a demanding job, while the mother finishes her work early and is home by 3 p.m. The family lives in a high crime neighborhood; drug dealing gangs recruit in the neighborhood. The mother and father are not involved in arranging or supervising activities for their adolescent son and his peers. The 14-year-old son is associating with antisocial youth in the neighborhood. 


\section{Identified Patient}

The father comes home late and does not help with chores at home. His 14-year-old son is rebellious, refuses to do chores at home, and has conduct problems at home and in school. He also comes home late, often very excited and irritable. He stays up much of the night listening to music, then sleeps deep into the day. The 11-year-old son is a model child.

\section{Conflict Resolution}

Conflicts are diffused through angry blaming and recriminations.

\section{General Discussion of the Diagnosis}

In the Guerrero family, the parents have assigned themselves separate role responsibilities. The mother is fully responsible for all child rearing, while the father's responsibility in this area is very limited. Because there appears to be an unspoken agreement between the parents to be distant from each other, it can be assumed that they both prefer their separate role responsibilities for their own reasons. This is maladaptive behavior in terms of child-rearing issues because the father and mother do not cooperate in parenting functions. Rather, it may appear that the mother and the troubled son are the ones allied, with father off on the side. If one looks a little further, it would not be surprising to find that the same patterns of interaction occur around content areas other than child rearing. In fact, these kinds of interactive patterns or structures are almost always found to re-occur in most aspects of family life. If they occur around one content, they are almost invariably occurring around most, if not all, contents. The lack of a strong parental alliance with regard to child-rearing issues undermines the family's ability to chart an effective and successful course of action. This is particularly troublesome when there are forces external to the family that influence the adolescent's development of behavior problems. These forces include the adolescent's peer group and the behavioral expectations that exist or to which the youth is exposed outside the home. These ecological forces provide training and opportunity for a full rebellion on the part of the adolescent.

A BSFT intervention will target changing the interactional patterns that are preventing the family from successfully charting the youth's path away from antisocial peer groups and externalizing behaviors. This intervention involves restoring parental leadership capabilities by first creating a parental leadership alliance.

In resonance, it becomes clear that because the father is outside of the mother-child alliance, he is less concerned about what goes on within that alliance. Because he "stays out," he is emotionally distant (disengaged) from both his wife and his son. In contrast to this, the mother and her 14-year-old son are much closer emotionally and psychologically, and, thus, they are likely to be enmeshed. Whether or not one defines the mother as enmeshed with the son or the mother and son as disengaged from the father, it is obvious that there 


\section{Planning Treatment Based on Diagnosis}

is a difference in the psychological and emotional distance that exists between father and mother and father and son on the one hand, and mother and son on the other.

On the dimension of developmental stage, it appears that the 14-yearold son may be burdened with emotional responsibilities that are more appropriately assigned to a spouse, such as being the mother's confidante. The other child is not allowed out after dark. This seems appropriate given the dangerousness of the neighborhood.

In this family, the identified patient is sometimes the troubled son and sometimes the isolated father. While the negativity the mother and the 14-year-old show toward the father functions to keep him out of the family, both the mother and father blame their current problems on their oldest son. If he were not rebellious, their separate role arrangement would work quite well for each of them. Unfortunately, conflicts between the mother and the father are not being resolved because their attempts to address their differences of opinion degenerate into blaming wars.

Understanding the dimensions that describe family interactions goes a long way toward helping the BSFT counselor define what he or she must do as a counselor: diagnose the problem in terms of specific dimensions of family interactions and then implement strategies to correct problems along these dimensions. Often some dimensions are more problematic than others and need to be the greater focus of the intervention. The counselor diagnosed the oldest son's drug abuse problem in terms of ineffective behavior control resulting from:

- Organization: absence of a parental subsystem that works together. Mother and father need to be assigned collaborative tasks that will bring them together.

- Organization: improper alliances. Boundaries must be strengthened between mother and 14-year-old son.

- Resonance: maladaptive boundaries in which one parent is too close (enmeshed) to the problem child, while a second parent is too far (disengaged) from the spouse and that same child. Boundaries need to be shifted so that the parents are closer to one another emotionally and interactionally, the children are more "in tune" with each other, and a healthy separation exists between the parents and the children.

- Developmental Stage: developmental stage may be inappropriate in that the enmeshed child is burdened and confused by a spousal role (confidante to mom's unhappiness with dad). The counselor should encourage the mother and father to serve as each other's support system. 
- Identified Patient: enmeshed child is identified by the family as its major problem. The counselor needs to shift the family's attention to help family members understand that the "whole system," rather than only the adolescent, is part of the problem. Also, family members need to eliminate negative attitudes and enabling behaviors they display toward the adolescent identified patient to "free" him to act in a socially appropriate manner.

- Life Context: 14-year-old identified patient is involved with a deviant peer group. The mother, father, and identified patient should negotiate rules and consequences for the adolescent's misbehavior, and boundaries between the family and the outside world need to be strengthened. Additionally, the parents may need to be more involved with the parents of their son's peers to make it easier to more effectively supervise their adolescent's activities.

- Conflict Resolution: family may have certain conflicts repeatedly occur and never get resolved because each time differences emerge, they (sometimes) are avoided and/or (most often) are diffused through blaming wars. The counselor should refocus the interaction on the problem each time family members attempt to avoid the issue or to change the subject so that the conflict may be negotiated and resolved.

\section{Producing Change}

Having diagnosed the problem in terms of these dimensions, the counselor was able to target interventions directly at the problematic interactions within these dimensions. One of the BSFT counselor's first moves was to help the disengaged father get closer to his estranged 14-year-old son. At the same time, the counselor initiated a dialogue between the two parents about this youth to try to establish an alliance between the parents around the content of their mutual concern for their son. The next step was help the parents negotiate rules for the youth that, once implemented, would bring his "outof-control" behavior under control. As these changes were being negotiated, the family displayed frequent conflict avoidance and diffusion. When the family attempted to diffuse or avoid the conflict, the counselor would intervene and return the topic of conversation to the original conflict. In the process, the family acquired new conflict resolution skills. The parents were able to agree on rules and consequences for the identified patient's behavior, and these were discussed and, where appropriate, negotiated between the parents and the son. Ultimately, the parents were able to set consistent limits, and the adolescent's behavior improved. 


\section{Case Example II: The Hernandez Family}

Clinical Presentation

\section{Establishing the Therapeutic System}

The Hernandez family was referred to the clinic by the public defender at the time of Isabelita's third arrest, this time for drug possession. Isabelita was 15 years old, and she lived with her mother, a single parent, and a 12-year-old brother. Because the mother only spoke Spanish, the case was assigned to a Hispanic BSFT counselor who called the home and heard screaming and fighting in the background. The counselor spoke with the mother, who sounded overwhelmed. When the counselor explained that he was calling to set up a family session, Ms. Hernandez angrily told the counselor that she could never get Isabelita to attend.

The counselor asked Ms. Hernandez for permission to come to the home when she and Isabelita were both likely to be home. Because Ms. Hernandez worked as a domestic during the day, the appointment was set for 7 o'clock the next evening. When the counselor arrived at the home, he found the mother alone with her 12-year-old son. Ms. Hernandez explained that Isabelita often stayed out with her friends, and she could not predict what time Isabelita would be home. The 12-year-old son was quick to confirm his mother's story and added that Isabelita was always upsetting his mother and that he wished she would just go away.

The counselor began to join with Ms. Hernandez by listening to the story of her hardships in this country and with Isabelita. Ms. Hernandez said how overwhelmed she felt by Isabelita's behavior and that she did not know what she could do. In fact, she said that, "It is all in God's hands now," as if there was nothing else she could possibly do. It appeared from the story that Ms. Hernandez did not have well-established rules or consequences for Isabelita's behavior. It also appeared that most of the communication that occurred between daughter and mother was angry, blaming, and fighting. Ms. Hernandez felt that they could argue for hours about the same thing and then have the same argument all over again the next day.

It was about 8:15 p.m., when Isabelita arrived. It was obvious to the counselor that her gait was unsteady and her speech was slurred. Her eyes were red. She barged into the home and went straight to the kitchen. When Ms. Hernandez said to Isabelita, "Come here, there is someone here who has come to see you about your arrest," Isabelita answered, " $\mathrm{F}-\mathrm{k}$ them, I am hungry."

Ms. Hernandez went to the kitchen to serve Isabelita her dinner, screaming at her "Your food is already cold. You are late again. We had dinner two hours ago." The screaming between mother and daughter continued for another 10 minutes before the counselor came to the kitchen to attempt to introduce himself to Isabelita, as a way of extending the joining process. In this first encounter, the counselor listened and joined. 


\section{Diagnosis}

While the counselor listened and joined, he also observed the interaction between mother and daughter. Armed with these observations, the counselor understood the family's interactions along the following BSFT diagnostic dimensions.

\section{Organization}

There is a problem with this family's hierarchy and leadership. The identified patient is in a powerful position, while the mother is powerless and feels overwhelmed. The mother has no control over the identified patient's behavior. There is no sibling subsystem. The 12year-old son triangulates between the mother and the identified patient.

\section{Resonance}

The family is very enmeshed. The quality of the enmeshment between the mother and the identified patient is conflictive and hostile.

\section{Developmental Stage}

All three members of this family appear to be functioning below what would be appropriate for their ages and roles. The identified patient's demands on her mother are those of a younger child, and she does not help out at home. The mother is overwhelmed and does not know how to control the identified patient. The son is too attached to his mother and involved in supporting her, and he does not engage in age-appropriate social and play activities.

\section{Life Context}

The family is new to the United States, and the mother is disconnected from her host society (e.g., she has no English skills). The identified patient spends most of her time with acculturated peers who participate in drug use and risky sex.

\section{Identified Patient}

The identified patient is extremely rigid. The identified patient centralizes herself with her negative behavior. The relationships between the identified patient and other family members are characterized by intense negativity. This family has not identified other problems or persons as a concern.

\section{Conflict Resolution}

The typical pattern of interacting in the family is continuous conflict emergence without resolution.

\section{General Discussion of the Diagnosis}

In the Hernandez family, the mother is overwhelmed and is unable to manage her drug-abusing daughter's behavior. The daughter, in turn, has distanced herself from the family and spends the majority of her time with sexually active and drug-using friends. When the 
daughter is home, she and her mother fight constantly, with the brother intervening to take the mother's side against his sister. The brother's triangulating maneuvers serve only to further isolate the identified patient from her family.

Cultural issues also need to be taken into account in diagnosing the Hernandez family. Upon their arrival in the United States from Colombia 3 years earlier, the members of this family began to drift apart from one another. Isabelita began learning English and associating with Americanized peers, whereas her mother remained socially and culturally isolated. Ms. Hernandez had become increasingly uncomfortable with Isabelita's acculturating behavior and choices of friends, but the widening chasm between mother and daughter discouraged Ms. Hernandez from addressing these issues with Isabelita. By the time Isabelita was referred to treatment, the family system had become completely dysfunctional, and Ms. Hernandez had ceded nearly all of her power and authority to her daughter.

\section{Planning Treatment Based on Diagnosis}

A powerful identified patient is typically joined first in order to engage the family into treatment. In this case, however, Isabelita did not present an engagement problem. Although angry and rebellious in her behavior, she was present in therapy and willing to voice her complaints and feelings. The counselor thus starts by joining both the mother and the identified patient. It is important very early in the therapy to work to restructure the dysfunctional family hierarchy. By supporting the mother, the counselor needs to help her break the cycle of conflict between herself and her daughter so that the mother can begin to recapture some control. Essentially, the counselor needs to help move the mother into an appropriate parental role. The brother's attempts at triangulation need to be blocked, allowing the mother and daughter to resolve their issues directly, between the two of them. This also would permit the brother to engage in more ageappropriate activities. Isabelita's disobedient behavior needs to be reframed as a cry for help in order to change the affective tone of her relationship with her mother, and, thus, to permit them to interact more positively.

The treatment plan that the BSFT counselor formulated for the Hernandez family addressed all six of the structural dimensions introduced in Chapter 3:

- Organization: A dysfunctional hierarchy exists in which the daughter holds the power and the mother is powerless and overwhelmed. Power must be transferred back to the mother.

- Organization: The son is triangulated into the relationship between the mother and the daughter. The son's attempts to triangulate must be blocked. 
- Resonance: The mother and the daughter are enmeshed in a conflictive and explosive relationship; the daughter's behavior must be reframed as a call for help to reduce the negativity.

- Developmental Stage: The daughter's behavior at home is immature and demanding, the son is playing a "mother's partner" role, and the mother does not assume appropriate parenting leadership. The daughter must be shown how to express her feelings, the mother must be encouraged to elicit and validate the daughter's feelings, and the son must be prompted to participate in ageappropriate social activities.

- Identified Patient: The daughter is designated as the source of the family's problems. The problem must be framed in terms of the whole family and addressed by changing the family's patterns of interaction.

- Life Context: Acculturation differences compound normative parent-adolescent disagreements and exacerbate the distance between the mother and the daughter. The counselor must help the two of them "get on the same page" in their interactions.

- Life Context: The daughter is associating with high-risk peers. As power is transferred back to the mother, peer selection must be brought up, and the mother needs to encourage the daughter to select different peers.

- Life Context: The mother and the son are socially isolated. The mother needs to familiarize herself with the English language and with American culture, and the son needs to associate with friends his own age.

- Conflict Resolution: The mother and the daughter tend to shout at and insult one another with no resolution. The family must be taught to stay on topic and resolve issues without leaving the room or resorting to personal attacks.

\section{Producing Change}

One week later, the counselor came for the second session, and the same exact incident re-occurred, with Isabelita coming home late, clearly on drugs. The counselor had already established a therapeutic relationship with the whole family. While the counselor sat with Ms. Hernandez waiting for Isabelita to show up, he used the time to explain how Ms. Hernandez could respond differently to Isabelita when she arrived home late (i.e., a reversal). In BSFT, therapy can be conducted with family members even when the identified patient is not present, as happened in this case. The counselor coached Ms. Hernandez to remain calm, not let Isabelita engage her in a screaming match, and not provide or help her with food. When Isabelita arrived, her portion of the family dinner had been placed in the freezer. Upon her arrival, Isabelita as usual bolted to the kitchen and demanded food. Encouraged by the counselor, Ms. Hernandez 
continued to sit in the living room, which, in their small home, was just next to the kitchen. Isabelita came into the living room and began shouting at her mother about the food. The mother yelled back to Isabelita, "You are a drug addict," and this began anew the cycle of blaming and recrimination. The counselor stood up, walked up to Ms. Hernandez, placed his hand on Ms. Hernandez's shoulder, and said, "You need to stay calm and not let her control you with her fighting." After several such interventions, Ms. Hernandez finally looked at the counselor and said, "I am trying to do it, but it is very hard." This statement represented Ms. Hernandez's initial step in using the counselor to help her detach from the conflict with her daughter. Furthermore, when the son stepped in, the counselor encouraged the mother to hold him back as well.

Isabelita continued to scream at her mother without getting a response for another 15 minutes before storming to her bedroom in a fury. Having been unsuccessful in engaging either her mother or brother in a fight, she was frustrated and gave up. After the counselor gave the mother ample support and praise for having controlled the situation and avoided a fight, the counselor moved the conversation to the next step. He discussed other ways in which Isabelita would "push her mother's buttons," and he gave Ms. Hernandez the task of using the newly learned skills on these other occasions.

This was a great gain for a single session, and it was clear that the gains from this session needed to be followed up and extended as soon as possible. The counselor told Ms. Hernandez that "we can keep making things better if we meet again in a few days." To Isabelita, the counselor said, "You see, these fights between you and your mom don't have to happen. If you'll agree to have me here again next week, we can keep working toward having peace in your life." As a result, both Ms. Hernandez and Isabelita agreed to hold another session the following week.

At the beginning of the next session, the counselor followed up on the previous week's gains by reviewing how Ms. Hernandez and Isabelita had made progress around the issue of fighting. The counselor intervened to block the brother's attempts to triangulate himself into interactions between Ms. Hernandez and Isabelita. Throughout the session, the counselor praised Ms. Hernandez whenever she avoided a fight, and empathized with her when she did not ("I understand how hard it is, but I know you tried."). The counselor also praised Isabelita amply for her ability to follow her mother's lead in avoiding fights that are "so upsetting to you." Hence, both the mother and Isabelita received credit and praise for accomplishing changes in their relationship. Having experienced a major accomplishment in placing the mother in control of the interactions, the counselor was now ready to move to the next level: negotiation of rules and consequences. The counselor also began to reinforce changes in Isabelita's 
behavior, no matter how small, by showing empathy for "how difficult all of this must be for you." The counselor also took an active role in helping Ms. Hernandez move into a more appropriate parental role by gradually praising each of the mother's attempts to guide or set limits for her daughter. The counselor also consistently reframed Isabelita's disrespectful behavior as a cry for help and as her way of expressing pain.

Gradually, over time, Isabelita's externalizing behavior and drug abuse decreased. Ms. Hernandez learned to befriend her daughter and to remain calm and not engage in conflict (i.e., a reversal) whenever Isabelita would throw a tantrum. Isabelita began to phrase her complaints in the form of respectful disagreements rather than hostile attacks. The brother, sensing that the tension between his sister and mother was decreasing, slowly backed away from the triangulated relationship with them and began to seek out his own social activities. 


